Research Article

\title{
Electromechanical Dynamic Behaviour and Start-Up Evaluation of Tumbling Ball Mills
}

\author{
Weidong Lv (D), Guoqiang Wang, and He Tian (D) \\ College of Mechanical Science and Engineering, Jilin University, Changchun 130022, China \\ Correspondence should be addressed to He Tian; tianhe1118@gmail.com
}

Received 7 June 2018; Revised 14 August 2018; Accepted 13 September 2018; Published 27 September 2018

Academic Editor: Zhengbiao Peng

Copyright (C) 2018 Weidong Lv et al. This is an open access article distributed under the Creative Commons Attribution License, which permits unrestricted use, distribution, and reproduction in any medium, provided the original work is properly cited.

\begin{abstract}
This paper presents a dynamic simulator of the electromechanical coupling start-up of a ball mill. The electromechanical coupling model based on the dynamic model of the ball mill, the characteristic equation of the clutch, and the dynamic model of the induction motor is established. Comparison between the simulation results of angular speed, load torque and current obtained from the model, and the experimental results is conducted to validate the correctness of these simulation results. Results show that the simulation results of the electromechanical model are highly consistent with the experimental results. Two indexes are proposed for evaluation. Finally, a $4500 \mathrm{~kW}$ ball mill is used to analyse the start-up process with different operation parameters of the air clutch. The effect of the engagement time and the pressure of the air clutch on the torque, current, and shock extent is analysed. Moreover, the optimum inflation time is determined.
\end{abstract}

\section{Introduction}

Ball mill is an important equipment in the field of mineral size reduction. Unlike semiautogenous (SAG) mills that operate with adjustable frequency drives, the ball mills work at a fixed speed [1]. Current research mainly focuses on the power draw model. However, the shutdown maintenance and the component consumption caused by the failure of the clutch friction disc wear and motor overheating, which increase the operating costs, are also important research topics. Therefore, the mill should be studied from the perspective of electromechanical coupling rather than only considering the mechanical system of barrel material. Castro and Valenzuela $[2,3]$ studied the electromechanical coupling model of a SAG mill. The simulation results were compared with the field record data during start-up and shutdown of the SAG mill. Guerrero and Pontt [4] investigated the oscillatory torque caused by dead time in the current control of a high-power gearless mill drive. Szolc et al. [5] examined the interaction of the electromechanical coupling of an asynchronous motor drive system. Laylabadi and Symonds [6] analysed the control system of an $18 \mathrm{MW}$ ball mill drive system.
The establishment and validation of the tumbling mill models have been widely conducted. Morrell [7] set up a power draw model of SAG mill that considers the slurry phase. Zolghadri et al. [8] developed a novel theory of breakage function. The method is considered for energy in comminution modelling of specific breakage energy. Salazar et al. $[9,10]$ established a dynamic model of SAG mill based on feed and discharge and the model predictive control method. Djordjevic et al. [11] used a prototype to study the law of particle breakage and energy distribution in the mill. A $\Phi 600 \mathrm{~mm}$ tumbling mill prototype was used to verify the DEM model in [12]. Therefore, the ball mill model is typically verified with a reduced proportion of prototypes.

The drive motor of the large ball mill is usually required to start with a reduced-voltage method [13]. Therefore, the large ball mill usually uses air clutch to assist start-up. During the start-up process, the motor is started up to the rated speed. Then, the ball mill is started through the engagement of the clutch. This study focuses on the dynamic behaviours of a ball mill and the dynamic characteristics of the induction motor. The electromechanical coupling model is established, and simulation of a $4500 \mathrm{~kW}$ ball mill during start-up is conducted. 


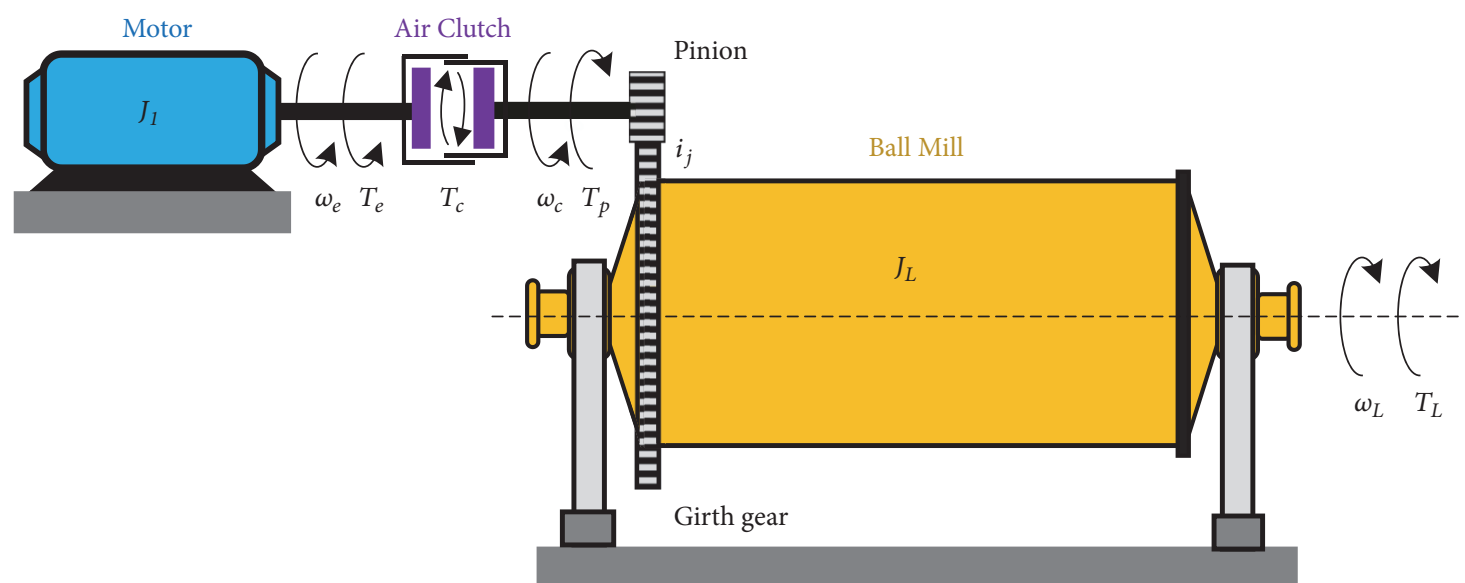

FIGURE 1: The schematic diagram of a ball mill driveline.

\section{Methodology}

2.1. Modelling of the Mechanical System. Figure 1 shows a ball mill driveline. The main shaft of the drive motor is connected to the driving disc of the air clutch. The driven disc of the air clutch is connected to the pinion shaft. $J_{1}$ is the moment of inertia of the motor rotor and clutch driving disc. $J_{2}$ is the equivalent moment of inertia of the pinion shaft. $i_{j}$ is the reduction ratio. $J_{L}$ is the moment of inertia of the rotary sections and materials of the ball mill. is

According to Figure 1, the dynamic model of the ball mill

$$
\begin{array}{r}
T_{e}-R_{\omega} \omega-T_{c}=J_{1} \frac{\mathrm{d} \omega_{e}}{\mathrm{~d} t} \\
T_{c}-\operatorname{sign}\left(R_{c}\right) T_{f}-T_{L}=J_{2} \frac{\mathrm{d} \omega_{c}}{\mathrm{~d} t}
\end{array}
$$

where $R_{\omega}$ is the rotation resistance coefficient of the drive motor, $T_{f}$ is the friction torque, and the rotation direction of the ball mill is determined by the sign function $\operatorname{sign}\left(\omega_{c}\right)$.

When the rotational speeds of the clutch are synchronised, i.e., $\omega_{e}=\omega_{c}$, the clutch no longer slips. The dynamic model can be written as follows:

$$
T_{e}-R_{\omega} \omega-\operatorname{sign}\left(\omega_{c}\right) T_{f}-T_{p}=\left(J_{1}+J_{2}\right) \frac{\mathrm{d} \omega_{c}}{\mathrm{~d} t}
$$

The large ball mill commonly uses a double-row heavyduty air clutch. The pressure of the friction surface is determined by the structure of the clutch. For the radial air clutch, the radial pressure generated by the compressed air can be calculated by the following formula:

$$
p_{c j}=2 \pi R_{t} B\left(p_{c \min }-p_{1}\right)
$$

where $R_{t}$ is the minimum radius of the air tube, $B$ is the width of the air tube, $p_{c \text { min }}$ is the minimum working pressure, and $p_{1}$ is the initial pressure.

After the air tube is inflated, it expands in the radial direction and overcomes the force of the return spring. As

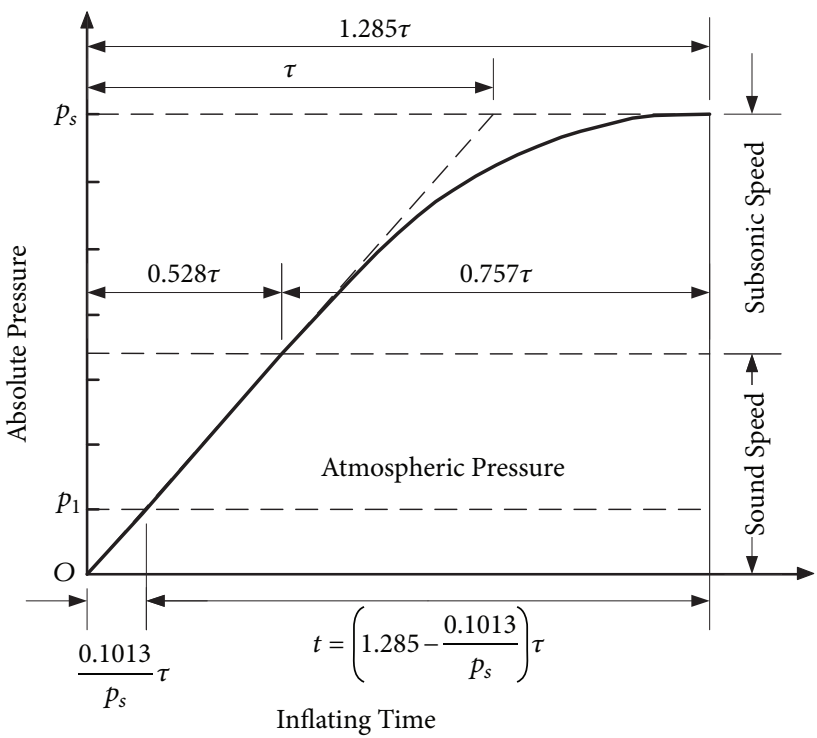

Figure 2: Curve of pressure versus time.

a result, the friction plate can hold the hub. Therefore, the pressing force is

$$
N=p_{c j}-\left(F_{c j}+Q\right)
$$

where $Q$ is the force of the return spring, $p_{c j}$ is the sum of the radial pressure generated by the compressed air through the air tube, and $F_{c j}$ is the sum of the centrifugal forces generated by all the parts that undergo radial displacement during operation of the clutch.

Figure 2 shows the curve of the pressure versus inflation time in accordance with the mechanical design manual. In $0-0.528 \tau$, the airspeed in the air tube is the speed of sound, and the inflator flow of the tire is constant. When the time exceeds $0.528 \tau$, the pressure difference between the air tube 
and air tank decreases, thereby decreasing the airspeed to the subsonic. The time constant can be calculated as follows:

$$
\tau=5.217 \frac{V}{k_{2} s} \sqrt{\frac{273}{T_{s}}}
$$

where $V$ is the container volume, $s$ is the effective crosssectional area of the inflation valve, $k_{2}$ is the isentropic exponent, and $k_{2}=1.3$ for air.

The clutch inflation time is generally around $10 \mathrm{~s}$, and the maximum friction torque of the clutch is generally greater than the maximum load torque of the ball mill. Therefore, this study assumes that the air pressure characteristics of the clutch are as follows:

$$
p_{c}=k_{c} p_{s} t
$$

where $k_{c}$ is a constant related to the inflation speed and $p_{s}$ is the air tank pressure.

The time from the start of the inflation to the contact (but not sliding) of the driving and driven discs is generally less than $3 \mathrm{~s}$. The inflation time is usually from $6 \mathrm{~s}$ to $12 \mathrm{~s}$. The relationship between clutch friction torque and pressing force can be expressed as

$$
T_{c}=\mu_{1} N_{c} A_{c}
$$

where $\mu_{1}$ is the coefficient of frictional torque and $A_{c}$ is the surface area of friction.

The radius and angle position of the mill charge centre of mass is commonly used for the ball mill dynamic model during start-up. This model considers that the mill load maintains its resting shape and that the mill is lifted to a certain angle depending on the mill speed and existing operating conditions during its rotation [3].

As shown in Figure 3, the mill torque is obtained as

$$
T_{L}=g M_{\text {load }} R_{u} \sin (\alpha)
$$

where $M_{\text {load }}$ is the mass of charge in the barrel, $R_{u}$ is the distance between mill centre and the centroid of the charge, and $\alpha$ is the deflection angle of the mill [14].

2.2. Modelling of the Induction Motor. The equation of state is established in Parker's synchronous coordinate system. When the rotor is a cage-type winding, an internal short circuit exists. The flux equation can be expressed as

$$
\begin{aligned}
& \frac{\mathrm{d} \psi_{s d}}{\mathrm{~d} t}=-R_{s} i_{s d}+\omega_{n} \psi_{s q}+u_{s d} \\
& \frac{\mathrm{d} \psi_{s q}}{\mathrm{~d} t}=-R_{s} i_{s q}-\omega_{n} \psi_{s d}+u_{s q} \\
& \frac{\mathrm{d} \psi_{r d}}{\mathrm{~d} t}=-R_{r} i_{r d}+\left(\omega_{n}-\omega\right) \psi_{r q} \\
& \frac{\mathrm{d} \psi_{r q}}{\mathrm{~d} t}=-R_{r} i_{r q}-\left(\omega_{n}-\omega\right) \psi_{r d}
\end{aligned}
$$

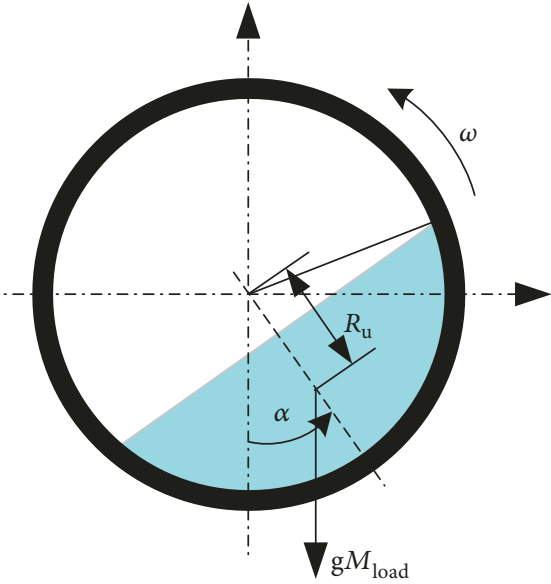

FIgURE 3: Scheme of circular sector load model [3].

The rotor current equation can be expressed as

$$
\begin{aligned}
& i_{r d}=\frac{1}{L_{r}}\left(\psi_{r d}-L_{m} i_{s d}\right) \\
& i_{r q}=\frac{1}{L_{r}}\left(\psi_{r q}-L_{m} i_{s q}\right)
\end{aligned}
$$

The torque equation can be expressed as follows:

$$
T_{e}=\frac{n_{p} L_{m}}{L_{r}}\left(i_{s q} \psi_{r d}-i_{s d} \psi_{r q}\right)
$$

According to formulas (9), (10), and (11), the state equation of the induction motor can be obtained as follows:

$$
\begin{aligned}
\frac{\mathrm{d} \omega}{\mathrm{d} t}= & \frac{n_{p}^{2} L_{m}}{J L_{r}}\left(i_{s q} \psi_{r d}-i_{s d} \psi_{r q}\right)-\frac{n_{p}}{J} T_{L} \\
\frac{\mathrm{d} \psi_{r d}}{\mathrm{~d} t}= & -\frac{1}{T_{r}} \psi_{r d}+\left(\omega_{n}-\omega\right) \psi_{r q}+\frac{L_{m}}{T_{r}} i_{s d} \\
\frac{\mathrm{d} \psi_{r q}}{\mathrm{~d} t}= & -\frac{1}{T_{r}} \psi_{r q}-\left(\omega_{n}-\omega\right) \psi_{r d}+\frac{L_{m}}{T_{r}} i_{s q} \\
\frac{\mathrm{d} i_{s d}}{\mathrm{~d} t}= & \frac{L_{m}}{\sigma L_{s} L_{r} T_{r}} \psi_{r d}+\frac{L_{m}}{\sigma L_{s} L_{r}} \omega \psi_{r q} \\
& -\frac{R_{s} L_{r}^{2}+R_{r} L_{m}^{2}}{\sigma L_{s} L_{r}^{2}} i_{s d}+\omega_{n} i_{s q}+\frac{u_{s d}}{\sigma L_{s}} \\
\frac{\mathrm{d} i_{s q}}{\mathrm{~d} t}= & \frac{L_{m}}{\sigma L_{s} L_{r} T_{r}} \psi_{r q}+\frac{L_{m}}{\sigma L_{s} L_{r}} \omega \psi_{r d} \\
& -\frac{R_{s} L_{r}^{2}+R_{r} L_{m}^{2}}{\sigma L_{s} L_{r}^{2}} i_{s q}-\omega_{n} i_{s d}+\frac{u_{s q}}{\sigma L_{s}}
\end{aligned}
$$

where $n_{p}$ is the number of pole pairs, the electromagnetic time constant of the rotor is $T_{r}=L_{r} / R_{r}, \sigma=1-L_{m}{ }^{2} /\left(L_{s} L_{r}\right)$ is the leakage coefficient of the motor.

From the dynamic equation (12), the input of the electromechanical system of the ball mill is two phase stator voltage, supply frequency, and load torque. 
2.3. Electromechanical Model of the Ball Mills. In accordance with the mechanical and induction motor dynamic models, the electromechanical coupling dynamic equation of the ball mill can be expressed as follows:

$$
\begin{aligned}
\frac{\mathrm{d} \omega_{e}}{\mathrm{~d} t}= & \frac{n_{p}^{2} L_{m}\left(i_{s q} \psi_{r d}-i_{s d} \psi_{r q}\right)-n_{p}\left(T_{c}+R_{\omega} \omega\right)}{J L_{r}} \\
\frac{\mathrm{d} \psi_{r d}}{\mathrm{~d} t}= & -\frac{1}{T_{r}} \psi_{r d}+\left(\omega_{n}-\omega\right) \psi_{r q}+\frac{L_{m}}{T_{r}} i_{s d} \\
\frac{\mathrm{d} \psi_{r q}}{\mathrm{~d} t}= & -\frac{1}{T_{r}} \psi_{r q}-\left(\omega_{n}-\omega\right) \psi_{r d}+\frac{L_{m}}{T_{r}} i_{s q} \\
\frac{\mathrm{d} i_{s d}}{\mathrm{~d} t}= & \frac{L_{m}}{\sigma L_{s} L_{r} T_{r}} \psi_{r d}+\frac{L_{m}}{\sigma L_{s} L_{r}} \omega \psi_{r q} \\
\frac{\mathrm{d} i_{s q}}{\mathrm{~d} t}= & \frac{R_{s} L_{r}^{2}+R_{r} L_{m}^{2}}{\sigma L_{s} L_{r}^{2}} i_{s d}+\omega_{n} i_{s q}+\frac{u_{s d}}{\sigma L_{s}} \\
& -\frac{R_{s} L_{r}^{2} T_{r}}{\sigma L_{s q} L_{r}^{2}}+\frac{L_{m} L_{m}^{2}}{\sigma L_{s} L_{r}} i_{s q}-\omega_{n} i_{s d}+\frac{u_{s q}}{\sigma L_{s}}
\end{aligned}
$$

2.4. Evaluation Index of the Ball Mill Start-Up Process. The evaluation of the start-up process of the ball mill aims to ensure successful start-up without the drive or clutch protection device that causes the mill to stop. Considering this condition, the start-up process is made as short as possible to reduce friction disc wear and heat generation. Therefore, the quantitative evaluation indexes of the start-up process of the ball mill can be set as the shock extent and motor protection to avoid vibration damage and tripping of the power.

(1) Shock Extent. During start-up of the ball mill, if the clutch engagement time is too fast, then the impact will cause damage to the drive motor and the conventional system. The shock extent can be expressed as the rate of change in the spindle angular acceleration [15], which is

$$
j=\frac{\mathrm{d} a}{\mathrm{~d} t}=\frac{\mathrm{d}^{2} \omega}{\mathrm{d} t^{2}}
$$

(2) Motor Protection. Too fast clutch engagement may cause the motor to the locked rotor and the relay to act. Therefore, during start-up, the drive motor should not be locked rotor and no overcurrent protection should be triggered. The current limit must be set in accordance with the motor parameters.

\section{Results and Discussion}

The simulation is based on a large ball mill with the parameters shown in Table 1 . The motor that matches the ball mill is a $4500 \mathrm{~kW}$ induction motor with the parameters shown in
TABLE 1: Parameters of the ball mill.

\begin{tabular}{lcc}
\hline Parameters & Units & Value \\
\hline The maximum diameter & $\mathrm{mm}$ & 5500 \\
Barrel length & $\mathrm{mm}$ & 8500 \\
Critical speed & $\mathrm{r} / \mathrm{min}$ & 18.4 \\
Loading mass & $\mathrm{t}$ & $60+340$ \\
Gear ratio & & 14.6 \\
Effective diameter & $\mathrm{mm}$ & 5300 \\
Working speed & $\mathrm{r} / \mathrm{min}$ & 13.7 \\
Filling ratio & & $30 \%-38 \%$ \\
Mass of the tumbling parts & $\mathrm{t}$ & 386 \\
\hline
\end{tabular}

TABLE 2: Parameters of the drive motor.

\begin{tabular}{lcc}
\hline Parameters & Units & Value \\
\hline Rated power & $\mathrm{kW}$ & 4500 \\
Rated speed & $\mathrm{r} / \mathrm{min}$ & 200 \\
Power factor & & 0.857 \\
Stator and rotor connection & & $\mathrm{Y}$ \\
Rated frequency & $\mathrm{Hz}$ & 50 \\
Rated voltage & $\mathrm{V}$ & 6000 \\
Rated Current & $\mathrm{A}$ & 303 \\
Effectiveness & & $92.6 \%$ \\
\hline
\end{tabular}

TABle 3: Parameters of the air clutch.

\begin{tabular}{lcc}
\hline Parameters & Units & Value \\
\hline The maximum friction torque & $\mathrm{Nm}$ & 246645 \\
Rated pressure & $\mathrm{MPa}$ & 0.56 \\
Moment of inertia & $\mathrm{kg} \cdot \mathrm{m}^{2}$ & 852.3 \\
Friction plate thickness & $\mathrm{mm}$ & 17 \\
The minimum hub diameter & $\mathrm{mm}$ & 1518 \\
The maximum speed & $\mathrm{r} / \mathrm{min}$ & 520 \\
Mass & $\mathrm{kg}$ & 4854 \\
Friction area & $\mathrm{cm}^{2}$ & 18060 \\
Air tube volume & $\mathrm{dm}^{3}$ & 32.8 \\
Centrifugal loss & $\mathrm{bar} / \mathrm{rpm}^{2}$ & $10.01 \times 10-6$ \\
\hline
\end{tabular}

Table 2. The parameters of the matching air clutch are shown in Table 3.

3.1. Optimum Inflation Time of the Air Clutch. The inflation time range of the air clutch is generally from $6 \mathrm{~s}$ to $12 \mathrm{~s}$. In accordance with the actual situation, this section sets the inflation time $\left(t_{i}\right)$ of the air clutch to $t_{i}=6 \mathrm{~s}, t_{i}=7 \mathrm{~s}, t_{i}=8 \mathrm{~s}, t_{i}=9$ $\mathrm{s}$, and $t_{i}=10 \mathrm{~s}$. The maximum friction torque is $100 \%$ of the maximum friction torque of the air clutch. Consistent with the actual start-up procedure, the results are plotted from the moment the clutch starts to engage for ease of analysis.

Figure 4 shows the speed comparison of the start-up process for different inflation times. Figure 4(a) shows the speed curve when the inflation time is $8 \mathrm{~s}$. As the rotational speed of the driven disc increases, the motor speed decreases. After the speeds of the driving disc and the driven disc are synchronized, the ball mill accelerates to the working speed. 


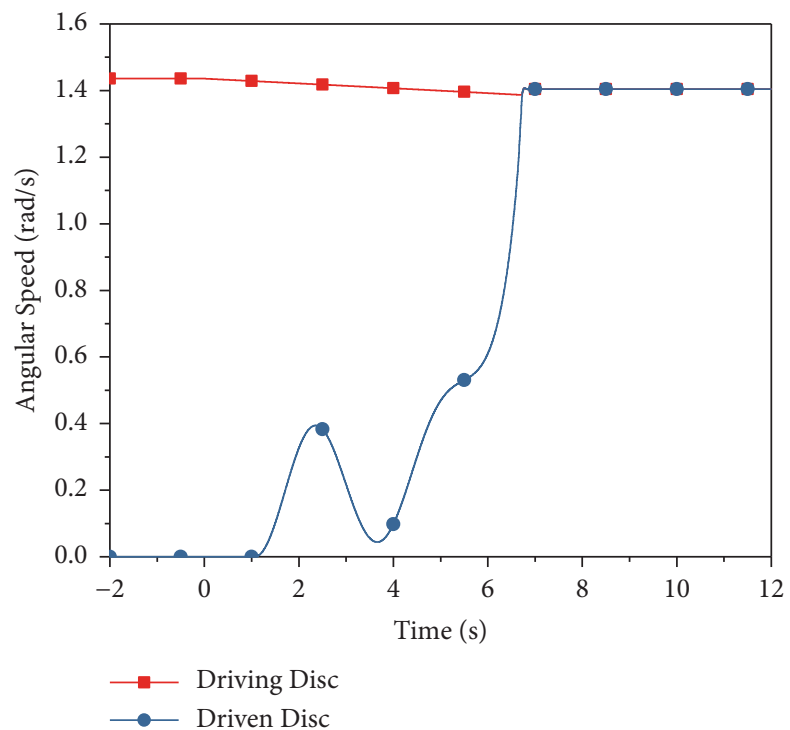

(a) $t_{i}=8 \mathrm{~s}$

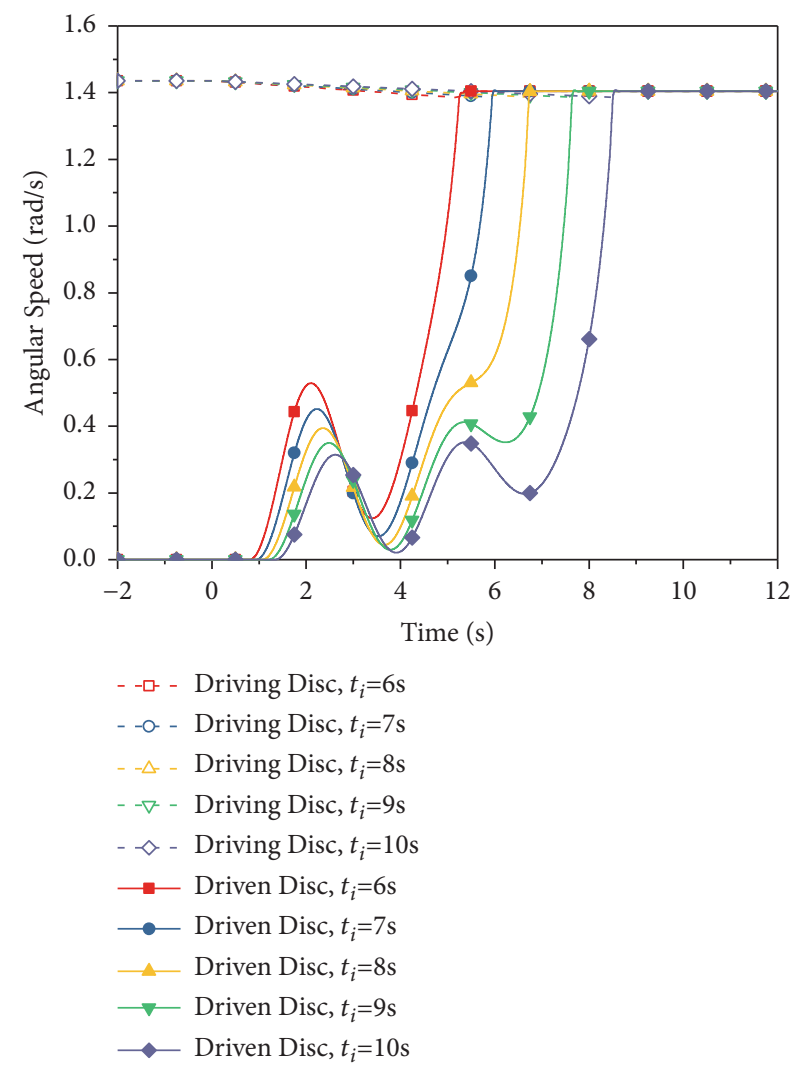

(b) The angular speeds of different $t_{i}$

FIGURE 4: The angular speeds versus time.

Because the mechanical characteristics of the large induction motor are hard, the amplitude of the speed decrease is small. Figure 4(b) shows the comparison of the angular velocity of the driven disc. The start-up time increases along with the increase in the inflation time. When $t_{i}=6 \mathrm{~s}$, the start-up time is $5.6 \mathrm{~s}$ and the engagement time is $5.2 \mathrm{~s}$. When $t_{i}=7 \mathrm{~s}$, the startup time is $6.2 \mathrm{~s}$ and the engagement time is $5.9 \mathrm{~s}$. When $t_{i}=8$ $\mathrm{s}$, the start-up time is $7.0 \mathrm{~s}$ and the sliding friction time is 6.7 $\mathrm{s}$. When $t_{i}=9 \mathrm{~s}$, the start-up time is $7.9 \mathrm{~s}$ and the engagement time is $7.6 \mathrm{~s}$. When $t_{i}=10 \mathrm{~s}$, the start-up time is $8.8 \mathrm{~s}$ and the engagement time is $8.5 \mathrm{~s}$. In general, as the inflation time decreases, the friction time of the driving and driven discs increases and the start-up time of the ball mill is slightly shorter than the inflation time. In the five cases, the ball mill barrel begins to rotate at approximately $1 \mathrm{~s}$ and the speed gradually increases. As the materials are lifted, the load torque gradually increases. The friction torque of the clutch is less than the load torque, and the rotational speed of the barrel decreases. The smaller the friction torque, the more the speed drops. As the magnitudes of the friction torque increase, the rotational speed increases again. The rotational speeds have been increased until the speeds of the driving and driven discs are the same for $t_{i}=6 \mathrm{~s}, t_{i}=7 \mathrm{~s}$, and $t_{i}=8 \mathrm{~s}$, respectively. The magnitudes of the rotational speeds fall again after the second increase $\left(t_{i}=9 \mathrm{~s}\right.$ and $\left.t_{i}=10 \mathrm{~s}\right)$. As the friction torque increases, the rotational speed increases again, which ends the friction process.

Figure 5 is the angle curve of the barrel. As shown in the picture, for all 5 inflation time, the angle of barrel increases steadily. Before the barrel was rotated by $90^{\circ}$, the rotation angle in the 5 inflation times shows changes in the growth rate. This law is consistent with the change law of the angular speeds in Figure 4 and is related to the torque.

Figure 6 shows the change in electromagnetic torque with the variation in inflation times. All the magnitudes of the electromagnetic torque increase as the friction torque increases during the friction process, and these magnitudes decrease as the load torque of the motor decreases when the rotational speeds of the driving and driven discs are synchronised. At $t_{i}=6 \mathrm{~s}, t_{i}=7 \mathrm{~s}$, and $t_{i}=8 \mathrm{~s}$, the electromagnetic torque is less than the load torque of the ball mill during the friction process. This variation is shown in Figure 7. This condition corresponds to the decrease in the rotational speed in Figure 4. Similarly, the electromagnetic torque is two times less than the load at $t_{i}=9 \mathrm{~s}$ and $t_{i}=10 \mathrm{~s}$. Therefore, the rising rate of the electromagnetic torque is positively correlated with the inflation time. Moreover, the electromagnetic torque at $t_{i}=6 \mathrm{~s}$ is slightly larger than that at the other conditions.

Figure 7 shows the curve of the theoretical friction torque of the clutch and the load torque of the ball mill. As the model 


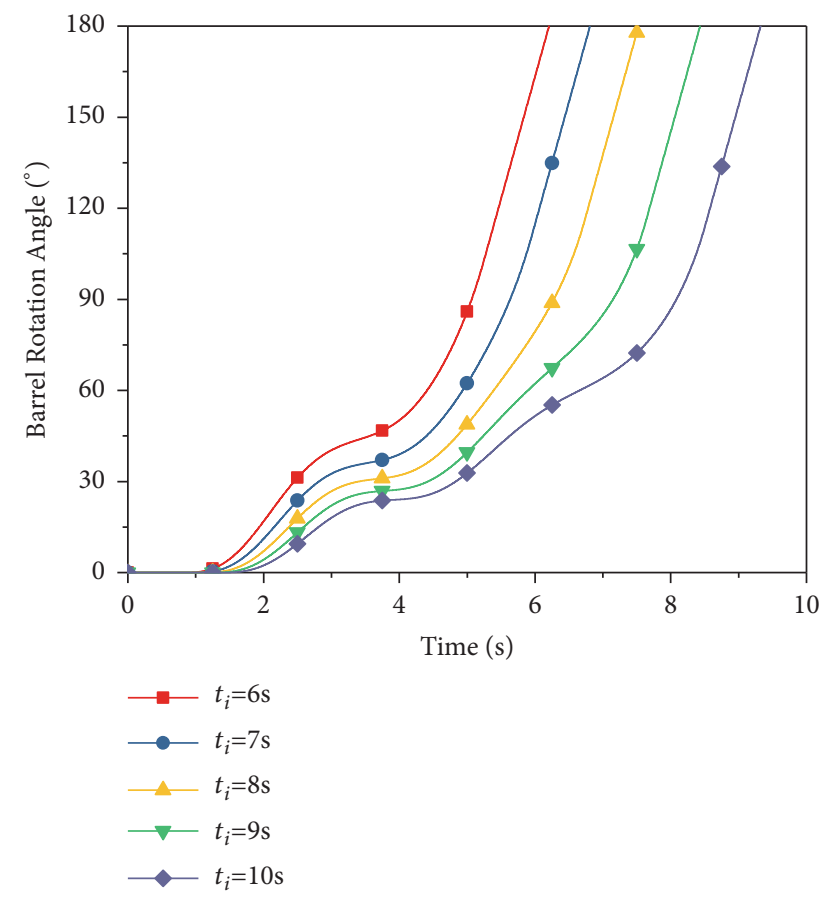

FIGURE 5: The rotation angle of the barrel versus time.

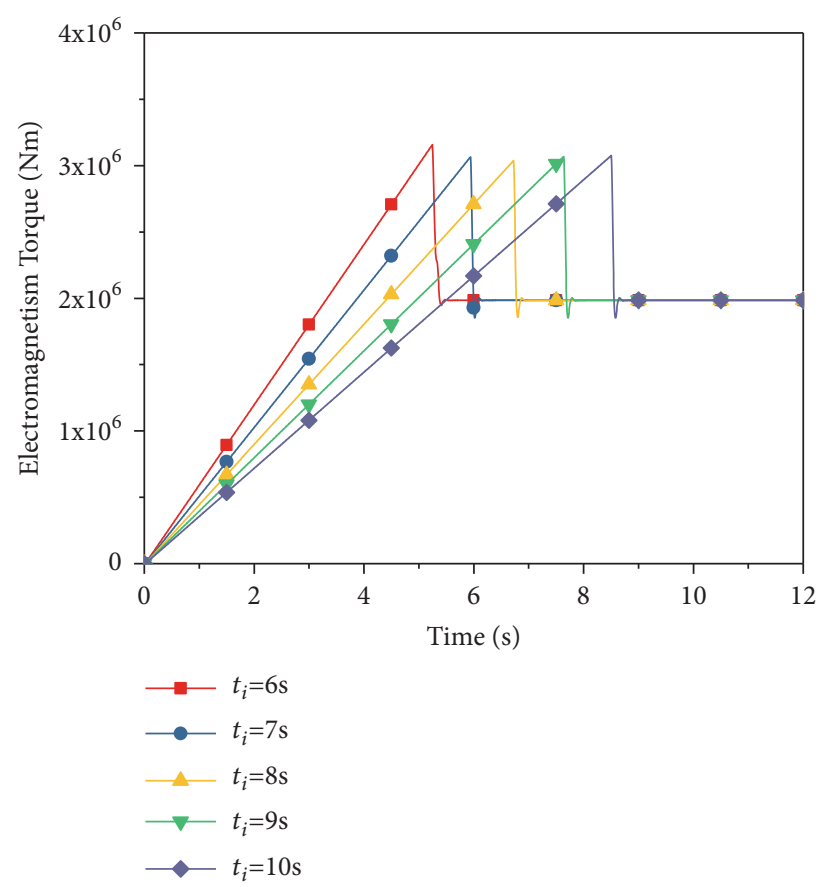

Figure 6: Effect of $t_{i}$ on the torque versus time.

of the mechanical system, the theoretical friction torque and the load torque are determined according to (7) and (8), respectively. For each of the 5 inflation times, the friction torque is less than the load torque of the ball mill for several times during the clutch engagement. This is shown in Figure 4 and Figure 5 as the decrease in angular speed and the increase in the deceleration of rotation angle. However, because the

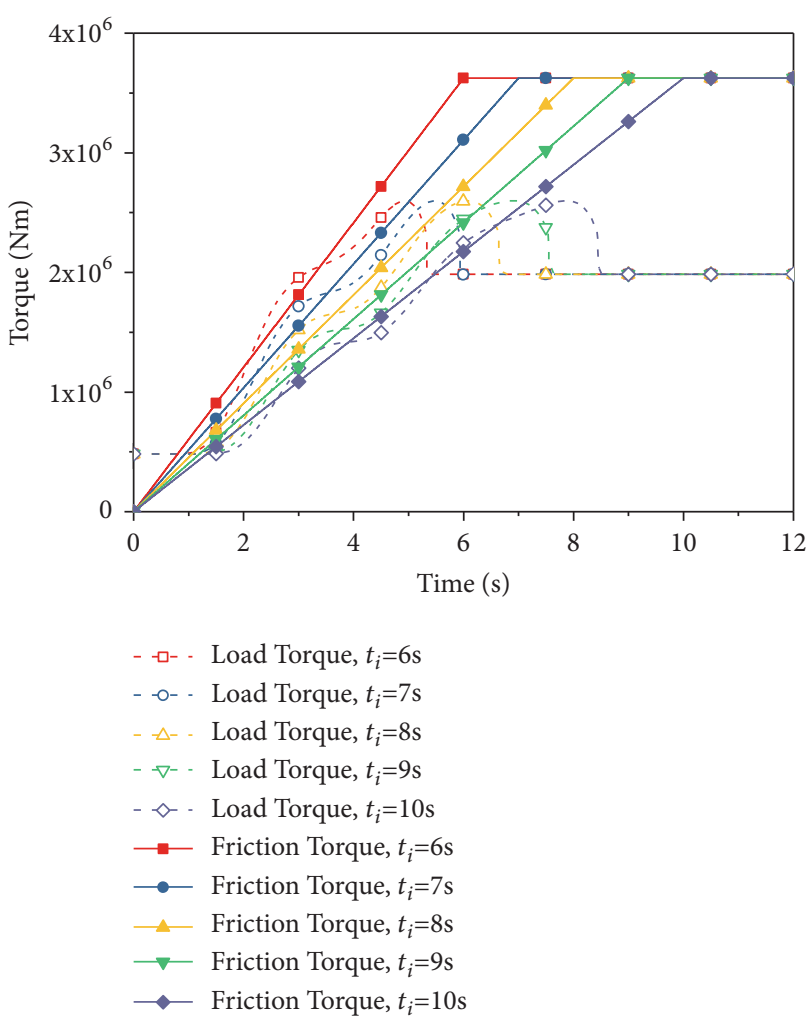

FIGURE 7: The theoretical friction toque and the load torque versus time.

angular speed does not drop to 0 and the barrel does not reverse, the ball mill is successfully start-up. The variation of electromagnetic torque can also be observed from Figure 6 . The electromagnetic torque changes based on the load torque of the motor. At the beginning of the air clutch engagement, the load torque of the motor is equal to the friction torque. When the friction torque is greater than the initial load torque (the static friction torque and the inertia torque), the driven disc beginning accelerates. When the friction torque is less than the load torque of the ball mill, the angular speed of the driven disc decreases. After the speeds of the driving disc and the driven disc are synchronized, the load torque of the motor is equal to the load torque of the ball mill. Although the theoretical friction torque still increases, as shown by the solid line in the Figure 7, the friction torque that the air clutch transmission is equal to the load torque of the ball mill. In addition, with the rotational speed and angle of the barrel increase, the material begins to cascade and fall, which causes the load torque of the ball mill decrease. Therefore, after the speeds of the driving and driven disc synchronized, the friction torque rapidly drops with the decrease of the load torque. In Figure 6, the data shows that the electromagnetic torque is linear increased at the beginning and then decreases.

Figure 8 shows the line current amplitude during the ball mill start-up. The currents which consist with the change in the electromagnetic torque in Figure 6 are gradually increased from the no-load current to the maximum value, dropped and stabilised at working current. The working 


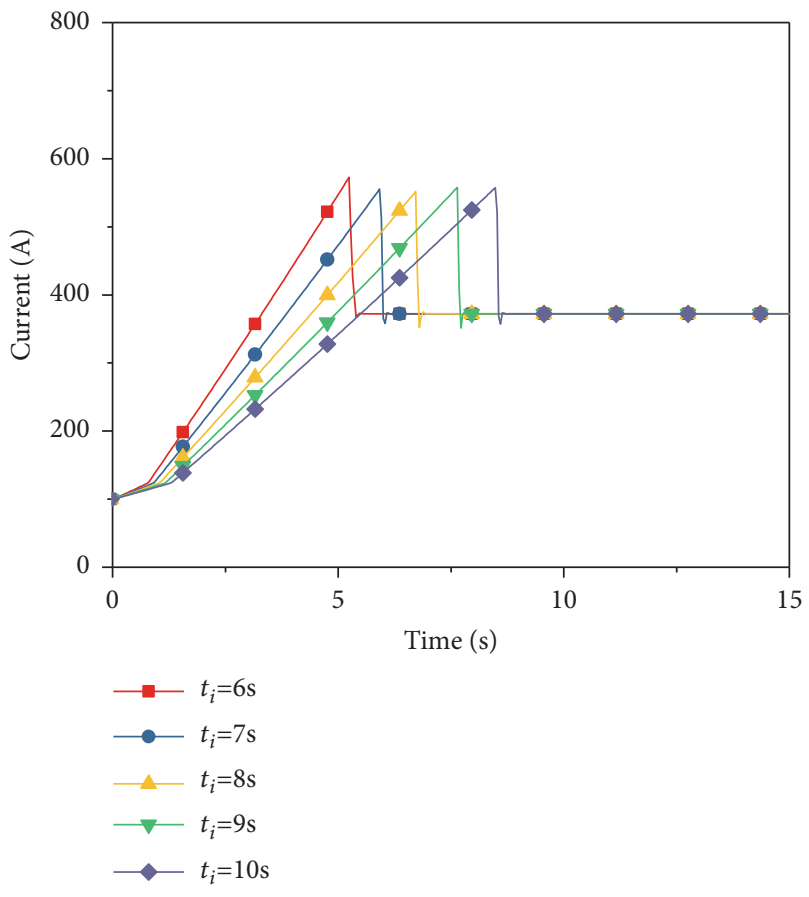

Figure 8: Effect of $t_{i}$ on the current versus time.

current is $349.2 \mathrm{~A}$. The maximum values of the phase current at $t_{i}=6 \mathrm{~s}, t_{i}=7 \mathrm{~s}, t_{i}=8 \mathrm{~s}, t_{i}=9 \mathrm{~s}$, and $t_{i}=10 \mathrm{~s}$ are $572.6,555.4$, $552.5,557.7$, and 557.4 A, respectively. Therefore, the suitable inflation time is from $7 \mathrm{~s}$ to $10 \mathrm{~s}$.

Figure 9 shows the curve of the shock extent. The shock extent is significant only in the friction process because the difference in the speeds of the driving and driven discs leads to impact. Thus, the peaks in the synchronous process can only reflect the value of acceleration. In general, the maximum peak of the shock extent decreases as the inflation time increases. The number of peaks increases as the start-up time increases. At $t_{i}=6 \mathrm{~s}, t_{i}=7 \mathrm{~s}$, and $t_{i}=8 \mathrm{~s}$, three peaks are observed during the mill start-up. Four peaks are observed at $t_{i}=9 \mathrm{~s}$ and $t_{i}=10 \mathrm{~s}$. The maximum values of shock extent are $70.4\left(t_{i}=6 \mathrm{~s}\right), 60.3\left(t_{i}=7 \mathrm{~s}\right), 52.8\left(t_{i}=8 \mathrm{~s}\right), 46.9\left(t_{i}=9 \mathrm{~s}\right)$, and 42.2 $\mathrm{rad} / \mathrm{s}^{3}\left(t_{i}=10 \mathrm{~s}\right)$. The optimal inflation time should be between $8 \mathrm{~s}$ and $9 \mathrm{~s}$ with the presence of shock extent.

The simulation results show that $t_{i}=8 \mathrm{~s}$ is appropriate for the ball mill. It not only ensures the success rate of the startup but also will not cause great impact and shock on the drive motor, the transmission system, and the mill.

\subsection{Inappropriate Inflation Time of the Air Clutch}

(1) Too Short Inflation Time. $t_{i}=3 \mathrm{~s}$ and $t_{i}=4 \mathrm{~s}$ are used in this simulation. Figure 10 shows the angular speed curves during the start-up process. In general, the motor can drive the ball mill to start. When $t_{i}=3 \mathrm{~s}$, the clutch reaches the synchronous process and working speeds at 2.5 and 2.9 s, respectively. When $t_{i}=4 \mathrm{~s}$, the clutch reaches the synchronous and working speeds at 3.6 and $3.9 \mathrm{~s}$, respectively.

Figure 11 shows the curve of the rotation angle of the barrel. The ball mill is successfully start-up in both inflation

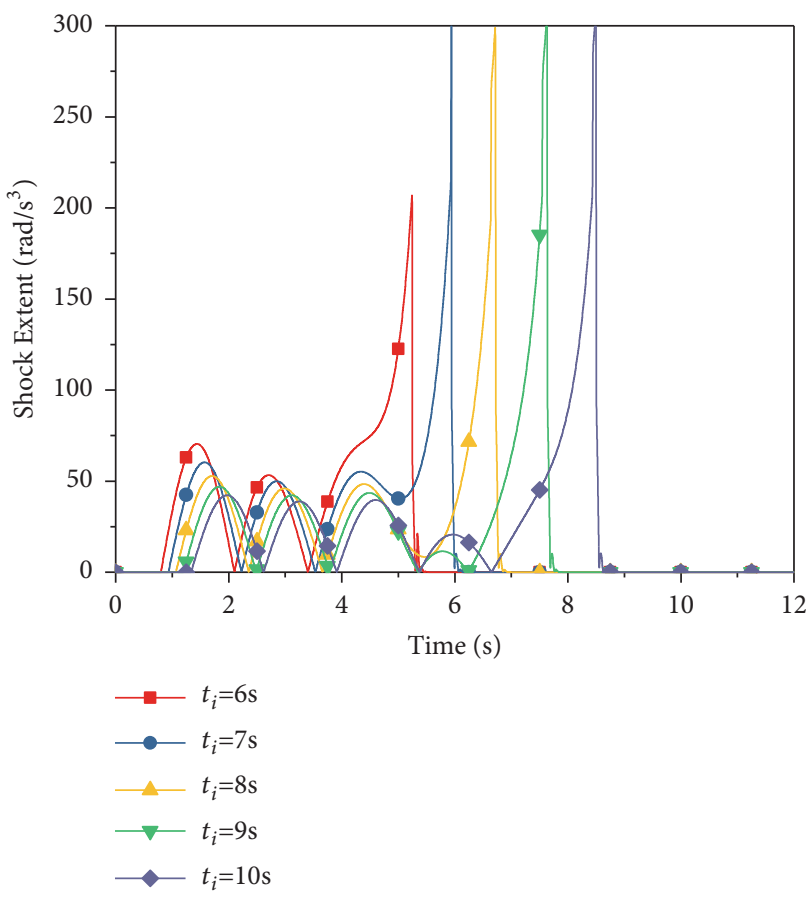

FIGURE 9: Effect of $t_{i}$ on the shock extent versus time.

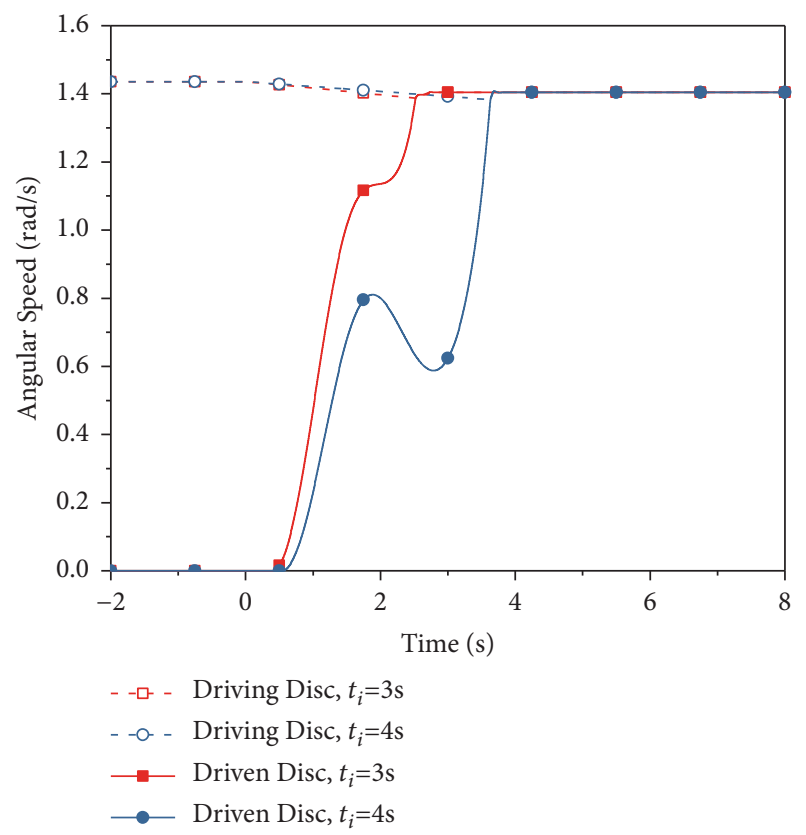

FIGURE 10: The angular speed of the clutch engagement too fast.

time. For $t_{i}=3 \mathrm{~s}$, the rotation angle increases smoothly. For $t_{i}=4 \mathrm{~s}$, the increase in rotation angle becomes slower at 2.8 $s$ because of the angular speed decrease. After the clutch is synchronized, the rotation angle constant increases in the working speed.

Figure 12 shows the curve of the electromagnetic torque versus time. The electromagnetic torque increases with the increase in the theoretical friction torque of the clutch. The 


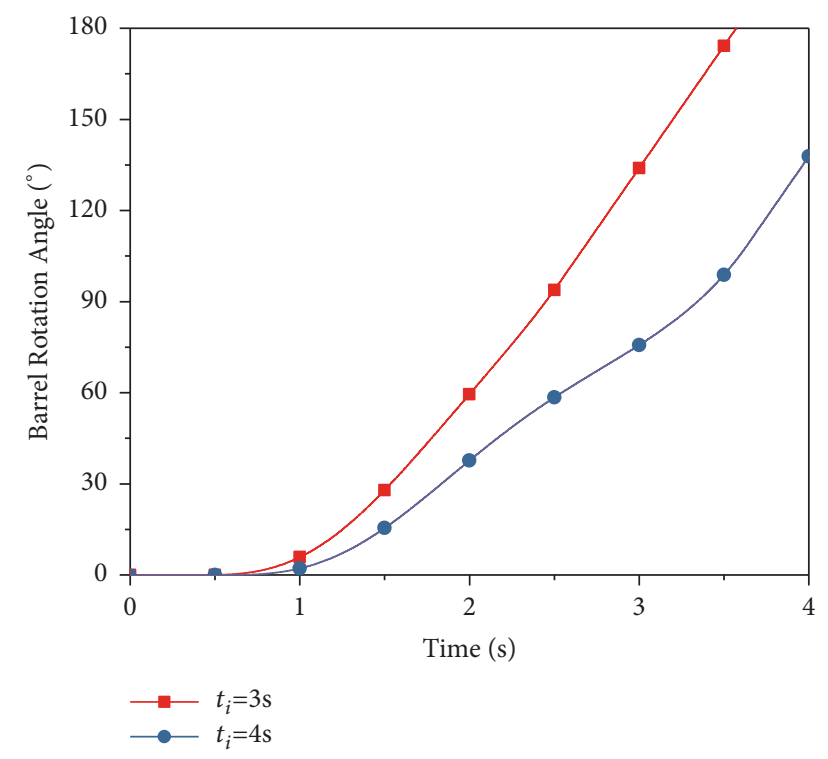

FIGURE 11: The barrel rotation angle of the too short inflation time.

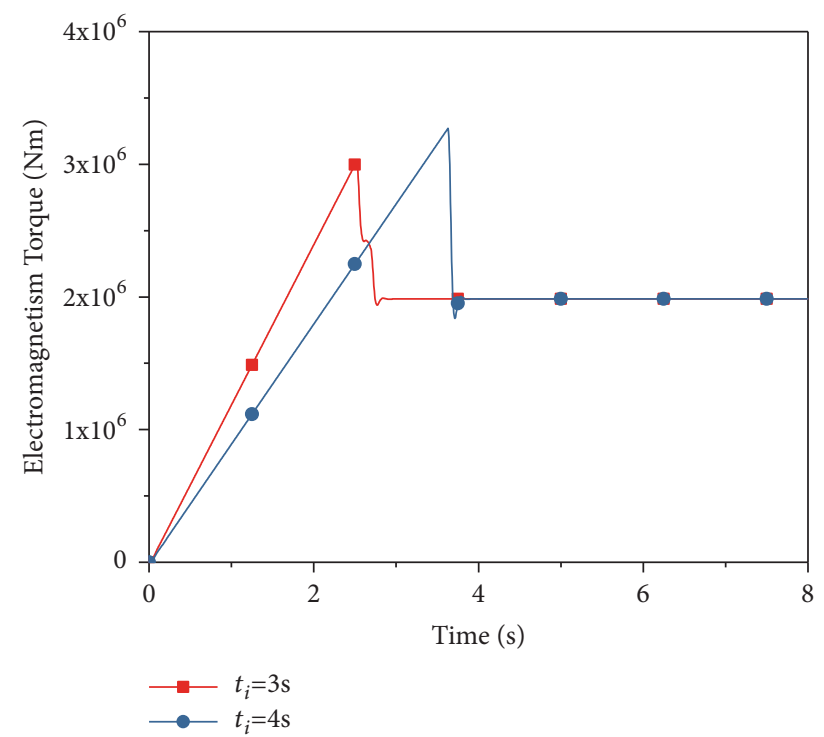

Figure 12: The electromagnetic torque of the too short inflation time.

mill starts to rotate at $0.5 \mathrm{~s}$. After the synchronisation of the driving and driven discs, the electromagnetic torque decreases to equal to the load torque.

Figure 13 shows the curves of the theoretical friction torque and the load torque. The theoretical torque increases linearly from 0 , and then reaches its maximum at the end of inflation time. For $t_{i}=3 \mathrm{~s}$, the theoretical friction torque is always greater than the load torque. Therefore, the angular speed of the driven disc does not decrease in Figure 10. For $t_{i}=4 \mathrm{~s}$, the theoretical friction torque is less than the load torque once. This is corresponding to the decrease in the angular speed of the driven disc and the reduction of the rotation angle growth rate in Figures 10 and 11, respectively.

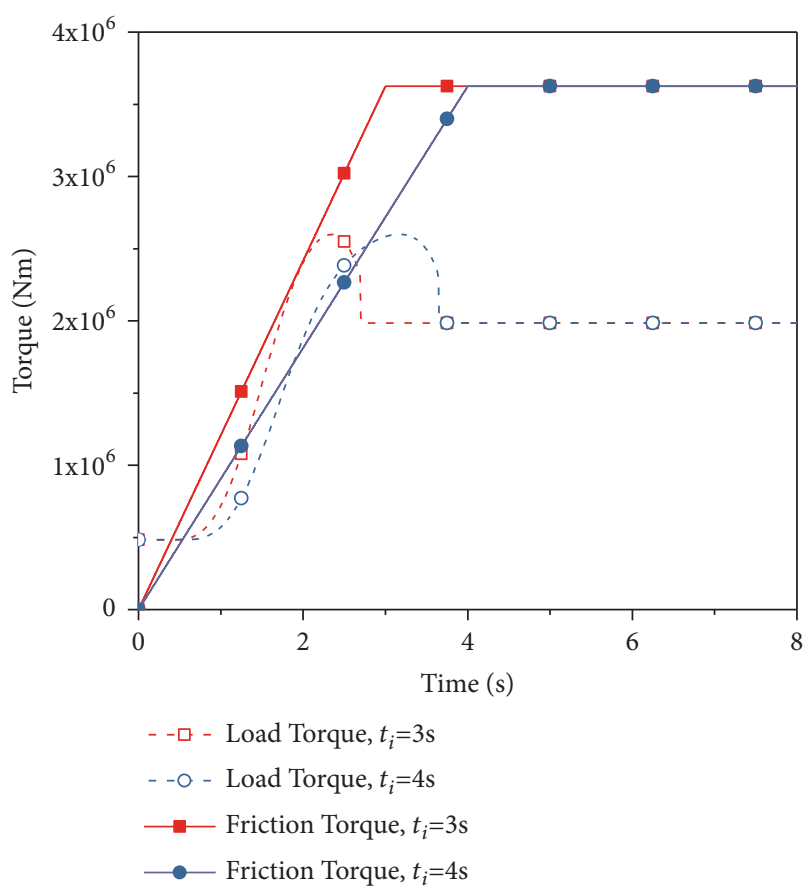

FIGURE 13: The theoretical friction torque and the load torque of the too short inflation time.

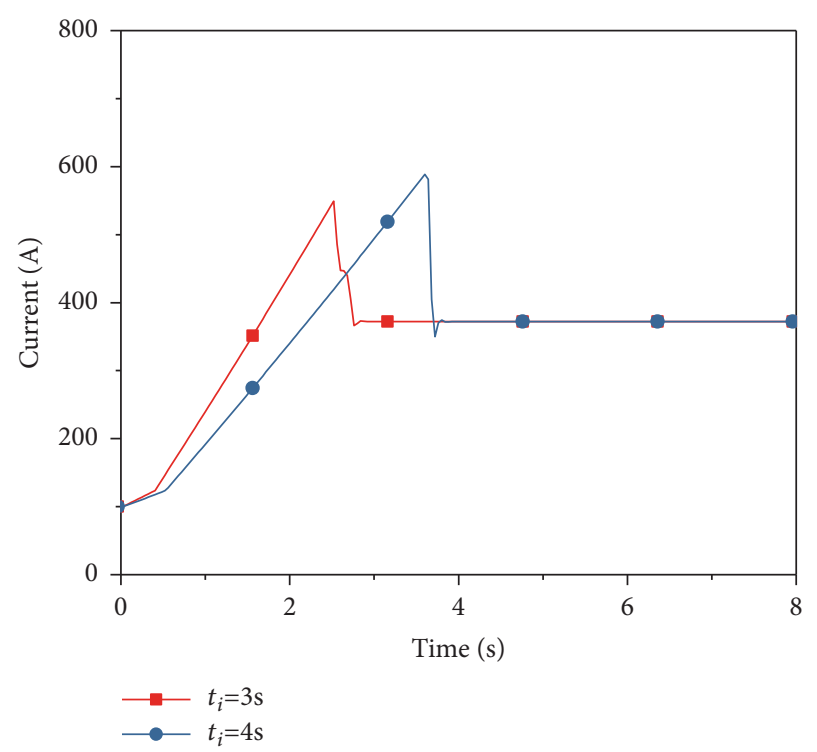

FIGURE 14: The current of the too short inflation time.

Figure 14 shows the curve of the current amplitude during the start-up process. The maximum currents are $549.3 \mathrm{~A}\left(t_{i}=3\right.$ $\mathrm{s})$ and $588.4 \mathrm{~A}\left(t_{i}=4 \mathrm{~s}\right)$. For $t_{i}=4 \mathrm{~s}$, the maximum current is 1.6 times more than the operating current. Although the peak is much smaller than the current during the motor start-up, it is still greater than $t_{i}=7-8 \mathrm{~s}$.

Figure 15 shows the curve of the shock extent. The peak of the shock extent during the friction process is $141 \mathrm{rad} / \mathrm{s}^{3}$ $\left(t_{i}=3 \mathrm{~s}\right)$. The shock extent reaches its peak for $1 \mathrm{~s}$ and afterward drops. The first peak of the shock extent for $t_{i}=4 \mathrm{~s}$ is 105.7 


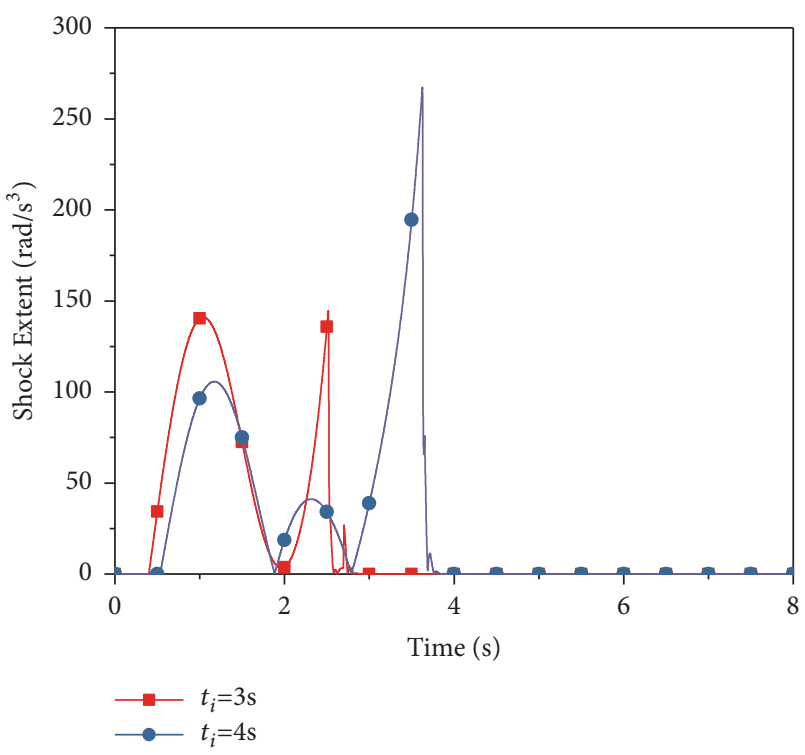

FIGURE 15: The shock extent of the too short inflation time.

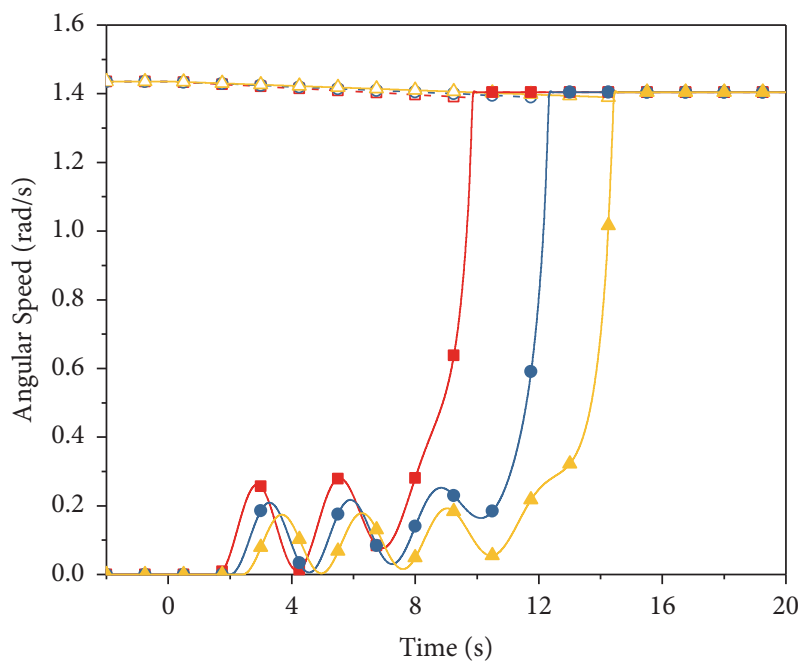

$$
\begin{aligned}
& -\square \text { Driving Disc, } t_{i}=12 \mathrm{~s} \\
& -\multimap \text { Driving Disc, } t_{i}=15 \mathrm{~s} \\
& -\square \text { Driving Disc, } t_{i}=18 \mathrm{~s} \\
& \longrightarrow \text { Driven Disc, } t_{i}=12 \mathrm{~s} \\
& \longrightarrow \text { Driven Disc, } t_{i}=15 \mathrm{~s} \\
& \longrightarrow \text { Driven Disc, } t_{i}=18 \mathrm{~s}
\end{aligned}
$$

FIGURE 16: The angular speed of the too long inflation time.

$\mathrm{rad} / \mathrm{s}^{3}$ at $1.1 \mathrm{~s}$. The second peak is $41 \mathrm{rad} / \mathrm{s}^{3}$ at $2.3 \mathrm{~s}$. The shock extent is twice as large as $t_{i}=7-8 \mathrm{~s}$. Therefore, the ball mill will be damaged during an actual start-up.

(2) Too Long Inflation Time. $t_{i}=12 \mathrm{~s}, t_{i}=15 \mathrm{~s}$, and $t_{i}=18 \mathrm{~s}$ are used to simulate too long inflation time. Figure 16 shows the angular speed curves of the driven disc. The result of $t_{i}=12 \mathrm{~s}$ is same as that of $t_{i}=10 \mathrm{~s}$. In particular, the speed curve has two fluctuations in the friction process. When $t_{i}=15 \mathrm{~s}$ and $t_{i}=18 \mathrm{~s}$, the curve has three fluctuations. The duration of the friction

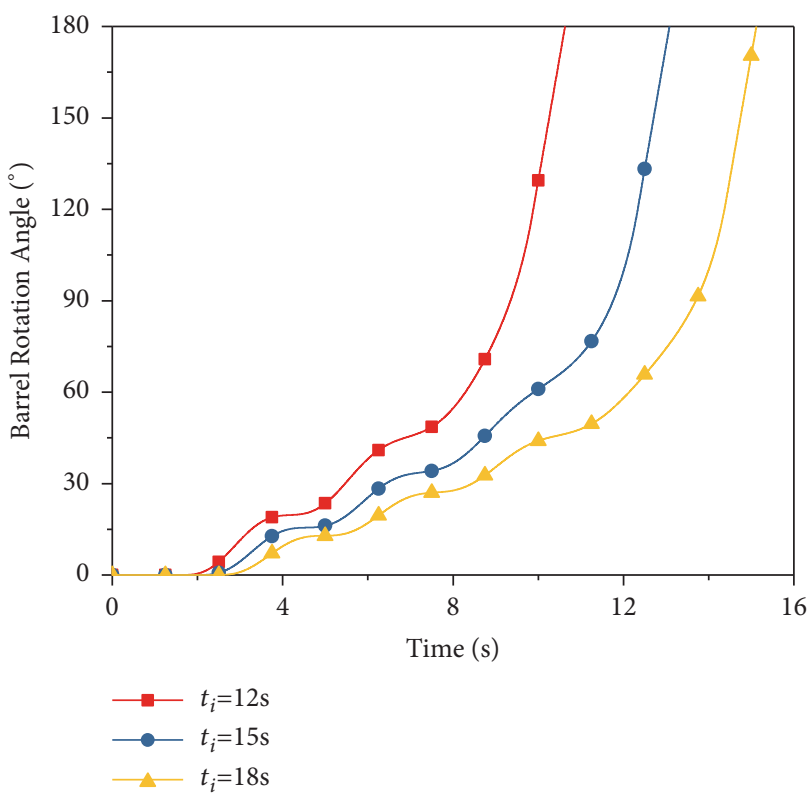

FIGURE 17: The barrel rotation angle of the too long inflation time.

process increases with the increase in the inflation time $(9.8 \mathrm{~s}$ at $t_{i}=12 \mathrm{~s}, 12.3 \mathrm{~s}$ at $t_{i}=15 \mathrm{~s}$ and $14.4 \mathrm{~s}$ at $t_{i}=18 \mathrm{~s}$ ). The start-up of the ball mill is close to $20 \mathrm{~s}$.

Figure 17 shows the curve of the barrel rotation angle when the inflation time is too long. The rotation angle growth rate is consistent with the variation of the angular speed. For the three inflation time, although the angular speed was very small at $4.2 \mathrm{~s}$, the barrel did not reverse. Therefore, the ball mill can be start-up successfully. Also, in the clutch engagement, the longer the inflation time the slower the increase in the angle of the barrel. After the speeds of the air clutch are synchronized, the acceleration is constant that the rotational speed was reached the working speed.

Figure 18 shows the curve of the theoretical friction torque and the load torque. For $t_{i}=12 \mathrm{~s}$, the theoretical friction torque is less than the load torque twice in the friction process, which is the same with the variation of the angular speed. For $t_{i}=15 \mathrm{~s}$ and $18 \mathrm{~s}$, the theoretical friction torque is less than the load torque for three times in the friction process. After the angular speeds synchronized, the actual friction torque is equal to the load torque, and decrease to the rated working torque of the ball mill. This variation is shown in Figure 18 as the process of current decrease.

Figure 19 shows the curves of the current versus time. The peaks of the current are $540 \mathrm{~A}\left(t_{i}=12 \mathrm{~s}\right), 541 \mathrm{~A}\left(t_{i}=15 \mathrm{~s}\right)$, and $527.7 \mathrm{~A}\left(t_{i}=18 \mathrm{~s}\right)$. Too slow clutch engagement increases the duration of the peak of the current. Moreover, the peak currents of three $t_{i}$ are similar. All the maximum currents of three $t_{i}$ are smaller than the maximum friction torque. Therefore, the extreme load of the drive motor does not change considerably as the clutch engagement slows down. The slower the engagement is, the longer the duration of the high current continues. In the meantime, the pressure on the grid and the drive motor increases. Thus, this condition should be avoided. 


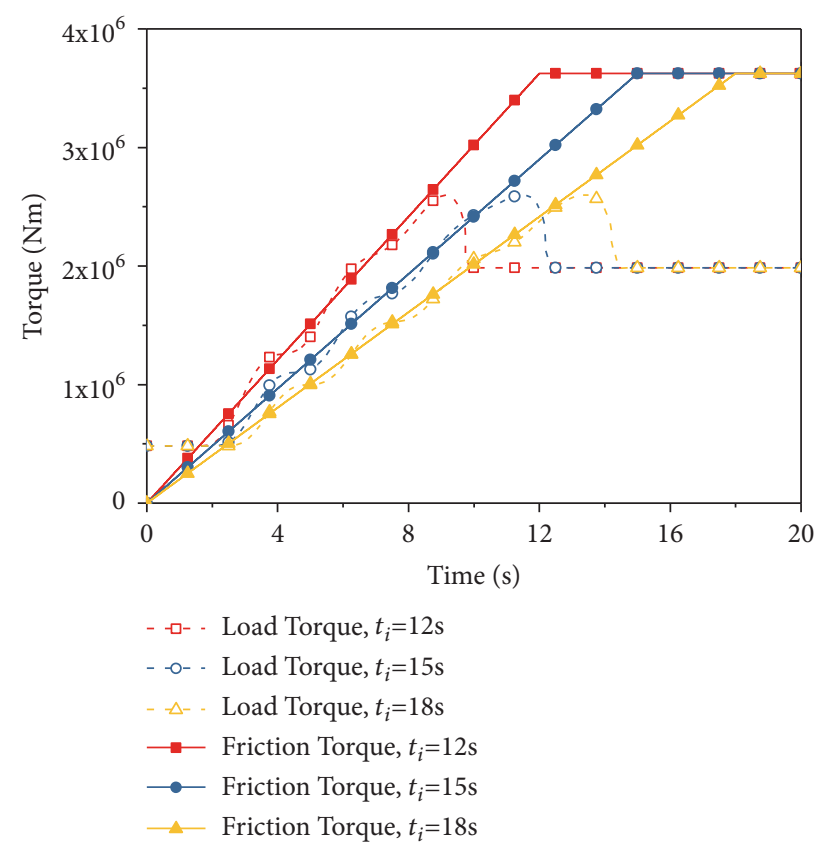

FIGURE 18: The theoretical friction torque and load torque of the too long inflation time.

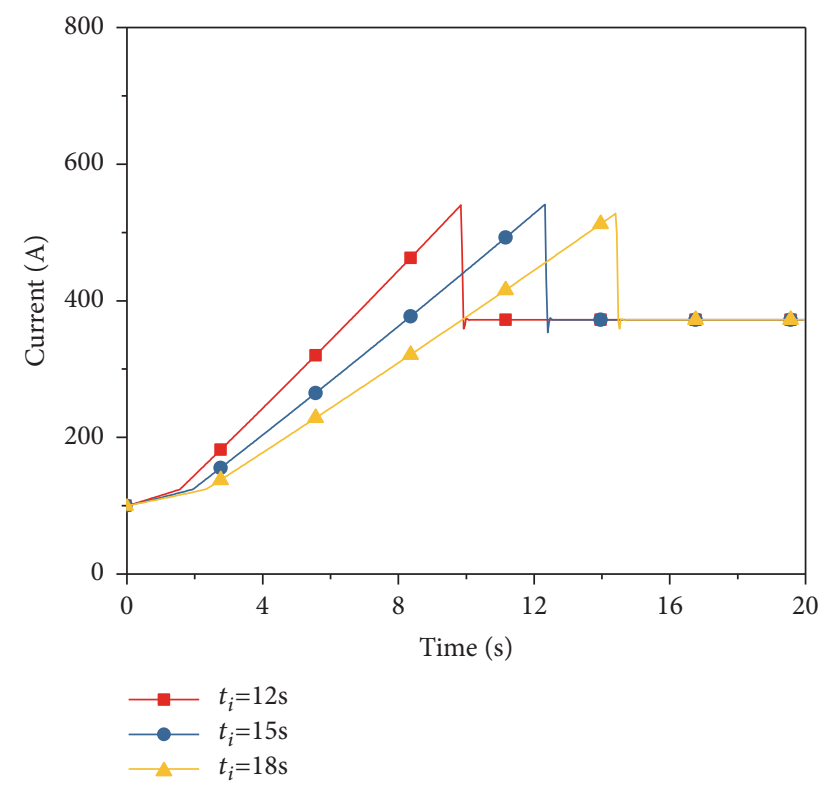

FIgURE 19: The current of the too long inflation time.

Figure 20 shows the shock extent. When $t_{i}=12 \mathrm{~s}$, the duration is $6.8 \mathrm{~s}$ and the peak is $35.2 \mathrm{rad} / \mathrm{s}^{3}$. When $t_{i}=15 \mathrm{~s}$, the duration is $8.1 \mathrm{~s}$ and the peak is $28.2 \mathrm{rad} / \mathrm{s}^{3}$. When $t_{i}=18$ $\mathrm{s}$, the duration is $10.1 \mathrm{~s}$ and the peak is $23.5 \mathrm{rad} / \mathrm{s}^{3}$. Compared with those in $t_{i}=7-8 \mathrm{~s}$, the amplitude is reduced by half, but the duration is doubled, which is inappropriate.

The results of this section show that the inflation time significantly affects the heat generation of the friction discs and the duration of the current. The change in the operation

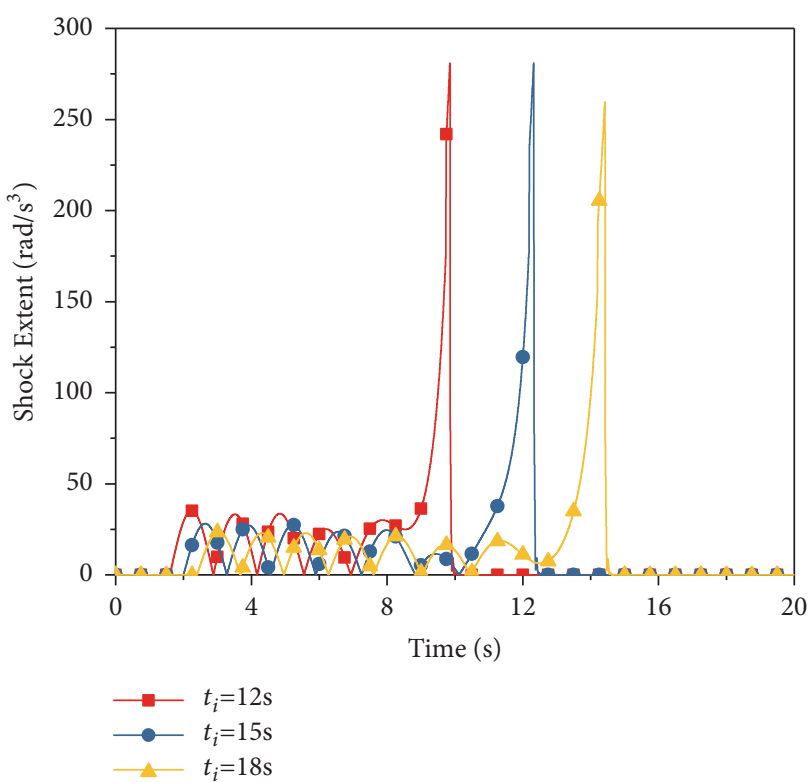

Figure 20: The shock extent of the too long inflation time.

parameters of the clutch should be strictly avoided after the optimal inflation time of the air clutch is determined.

3.3. Change in Air Pressure. This section assumes that the pressure of the air tank has changed. Therefore, the maximum friction torque $\left(T_{f \max }\right)$ of the clutch decreases or increases. The settings used are as follows: $t_{i}=7 \mathrm{~s}$ and $T_{f}=80 \% T_{f \max }, T_{f}=T_{f \max }, T_{f}=120 \% T_{f \max }, T_{f}=160 \% T_{f \max }$, and $T_{f}=200 \% T_{f \text { max }}$.

Figure 21 shows the curve of the angular speed of the five conditions. The ball mill can successfully start even under air pressure loss $\left(T_{f}=80 \% T_{f \text { max }}\right)$. In the meantime, the duration of the high current and friction process increases. In addition, if $T_{f}<80 \% T_{f \text { max }}$, then the ball mill will fail to start. The greater the friction torque at constant $t_{i}$, the faster the clutch engagement and the smaller the fluctuation of speed. The speed has two fluctuations at $T_{f}=80 \% T_{f \max }$. The others only have one fluctuation. The fluctuation decreases with the increase in the friction torque.

Figure 22 shows the rotation angle curve of the ball mill start-up with different air pressures of the air clutch. The increasing rate of the rotation angle corresponds to the change in the angular speed. For the five $T_{f}$, although the angular speeds are all decreased during the mill startup, the barrel is not reversed. Therefore, the ball mill can be successfully started under the five working conditions. Moreover, the smaller the air pressure is, the slower the rotation angle increasing rate will be.

Figure 23 shows the curve of the theoretical friction torque and the load torque. When the inflation time is constant, increasing the air pressure is equivalent to increasing the inflation speed. For $T_{f}=80 \% T_{f \text { max }}$, the number of times which the theoretical friction torque is less than the load torque is more than other conditions, and the duration is longer. This results in a greater fluctuation in the angular 


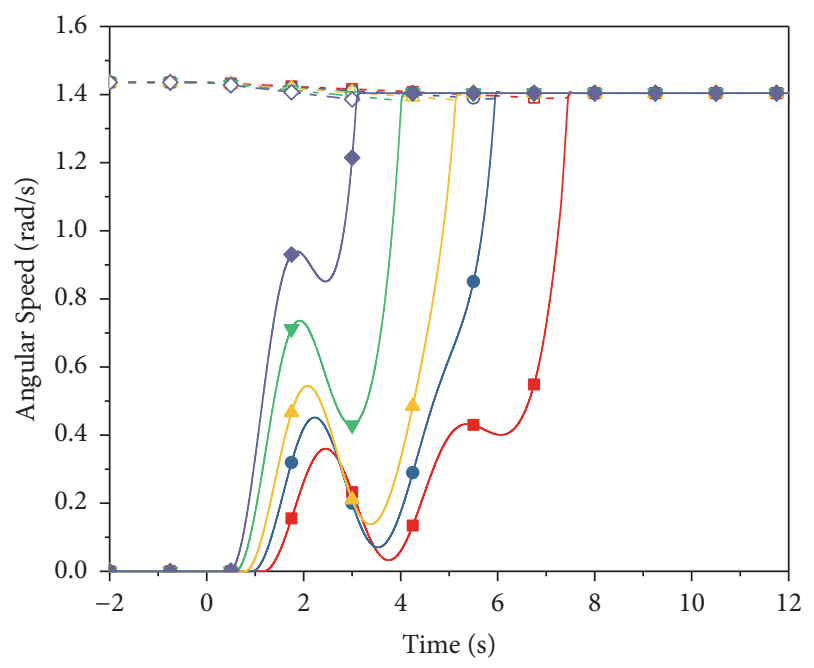

$$
\begin{aligned}
& \text { - 느 - Driving Disc, } T_{f}=80 \% T_{f \max } \\
& \text { - - - - Driving Disc, } T_{f}=100 \% T_{f \max } \\
& \triangle \text { Driving Disc, } T_{f}=120 \% T_{f \max } \\
& \nabla \text { - Driving Disc, } T_{f}=160 \% T_{f \max } \\
& \text { - } \diamond \text { - Driving Disc, } T_{f}=200 \% T_{f \max } \\
& \longrightarrow \text { Driven Disc, } T_{f}=80 \% T_{f \max } \\
& \longrightarrow \text { Driven Disc, } T_{f}=100 \% T_{f \max } \\
& \text { —_ Driven Disc, } T_{f}=120 \% T_{f \max } \\
& \longrightarrow \text { Driven Disc, } T_{f}=160 \% T_{f \max } \\
& \longrightarrow \text { Driven Disc, } T_{f}=200 \% T_{f \max }
\end{aligned}
$$

FIGURE 21: Effect of $T_{f}$ on the angular speed versus time.

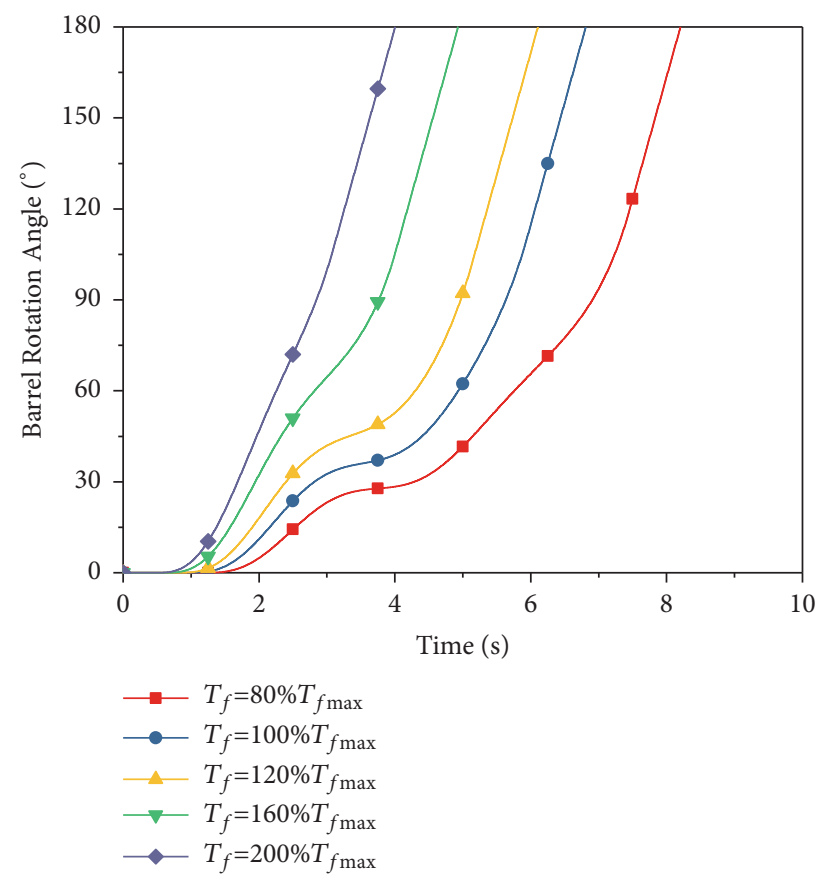

Figure 22: The rotation angle of the barrel versus time.

speed, as shown in Figure 21. It is also reflected in the increase in the duration of the shock extent in Figure 25. Therefore, the air pressure loss must be avoided.

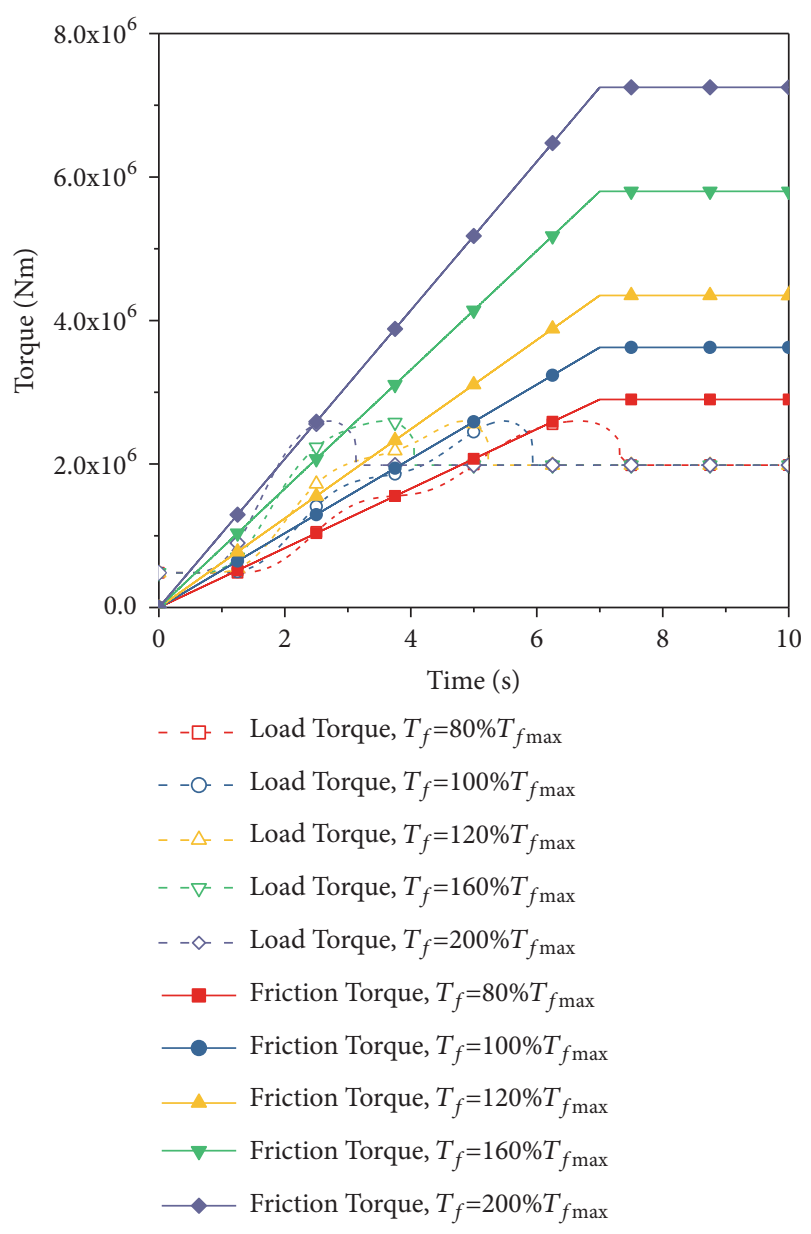

FIGURE 23: The theoretical friction torque and the load torque versus time.

Figure 24 shows the electromagnetic torque during the start-up process. The friction torque of the clutch is sufficiently large. Thus, the increase in $T_{f}$ cannot affect the peak of the electromagnetic torque. The electromagnetic torque does not reach the friction torque during the friction process. Therefore, the increase in the air pressure corresponds to the decrease in the inflation time.

Figure 25 shows the shock extent of the five conditions. As $T_{f \text { max }}$ decreases, the amplitude of the shock extent decreases and the duration increases. When $T_{f}=80 \% T_{f \max }$, the peak of the shock extent is similar to $T_{f}=T_{f \max }$. Therefore, the air pressure should be constant after the clutch parameter is determined.

\section{Conclusion}

In this study, the electromechanical coupling dynamic model of a single-motor edge-driven ball mill is established. Then, the start-up process of a large-scale ball mill is simulated. The electromechanical performance of the ball mill is evaluated in terms of the shock extent and current. The conclusions based on the observations, calculations, and analyses are as follows. 


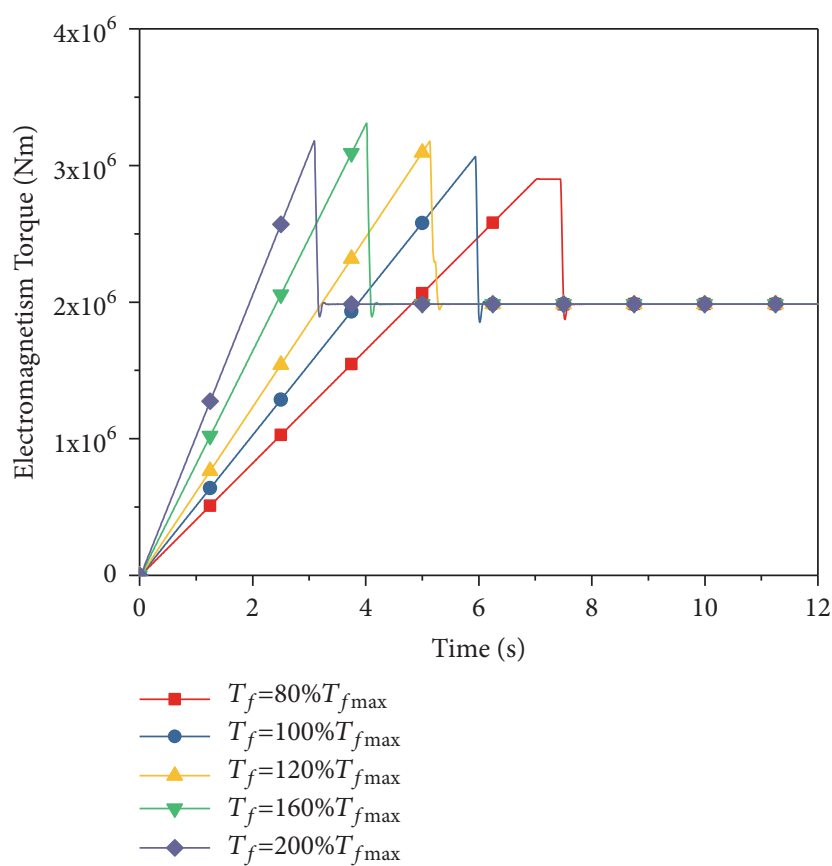

FIGURE 24: Effect of $T_{f}$ on the electromagnetic torque versus time.

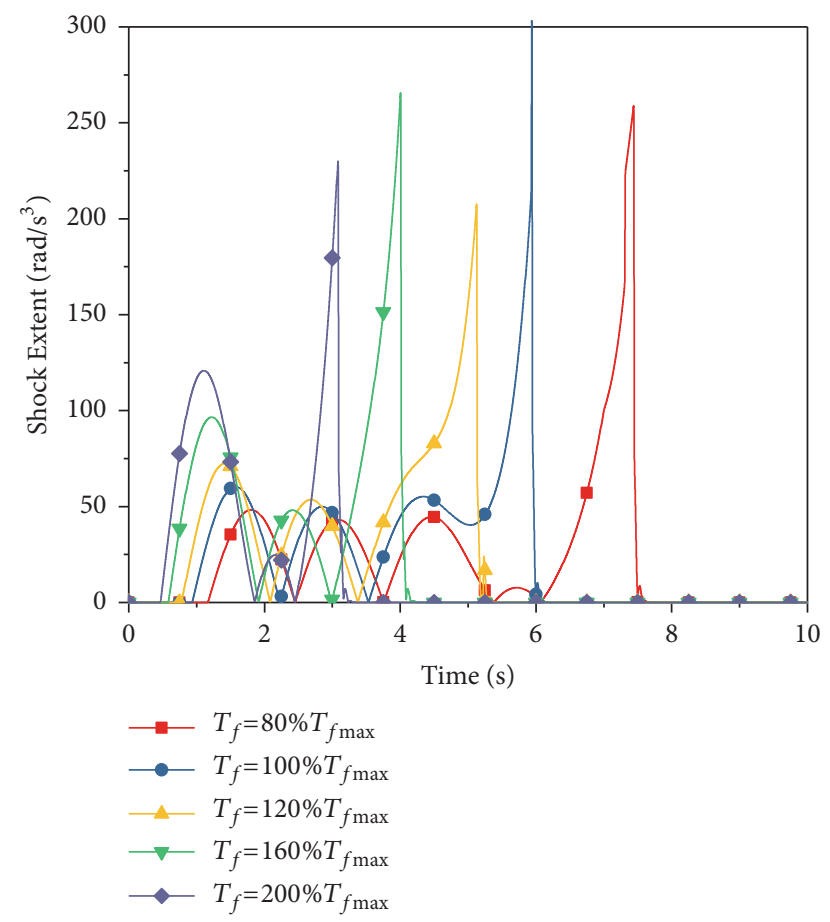

FIGURE 25: Effect of $T_{f}$ on the shock extent versus time.

Changes in the parameters of the air clutch can cause the changes in the clutch engagement. In the friction process, the angular speed of the driven disc may decrease during the increase of the synchronous rotational speed. The reason for the fluctuation can be explained as follows: at this moment, the friction torque that the air clutch can transmit is smaller than the torque generated by the rotation of the ball mill.
However, as long as the barrel does not reverse and the rotation angle keep increasing, the angular speed of the driven disc fluctuation will not cause failure of the ball mill start-up.

The shock extent is too large when $t_{i}$ is too short, and this condition will damage the air clutch. Although the shock extent decreases with the increase in $t_{i}$, the duration of the peak current and the friction time of the clutch increase, which generates a large amount of heat. As a result, the life of the drive motor and the clutch friction disc decrease, and this condition should be avoided.

When the air pressure of the clutch increases, which is similar to the decrease in $t_{i}$, the shock extent increases. Although some pressures are lost, the ball mill can still start up (20\% in this study). However, the duration of the current will increase. Therefore, the pressure should be monitored. If the pressure is lost, the start-up of the ball mill should be stopped.

\section{Notations}

$A_{c}: \quad$ The surface area of friction

$B: \quad$ The width of the air tube

$F_{c j}$ : The sum of the centrifugal forces

$i_{j}$ : $\quad$ Reduction ratio

$J_{1}$ : The moment of inertia of motor rotor and clutch driving disc

$J_{2}$ : $\quad$ The moment of inertia of the pinion shaft

$J_{L}: \quad$ The moment of inertia of the rotary sections and materials of the ball mill

$j: \quad$ Shock extent

$k_{2}$ : The isentropic exponent

$k_{c}$ : $\quad$ A constant which is related to the inflation speed

$M_{\text {load }}$ : The mass of charge in the barrel

$N$ : $\quad$ The pressing force

$n_{p}: \quad$ The number of pole pairs

$p_{s}: \quad$ The air tank pressure

$p_{1}: \quad$ The initial pressure

$p_{c j}$ : The radial pressure generated by the compressed air

$p_{c \text { min }}$ : The minimum working pressure

$Q: \quad$ The force of the return spring

$R_{t}$ : The minimum radius of the air tube

$R_{u}$ : The distance between mill centre and the centroid of the charge

$R_{\omega}: \quad$ The rotation resistance coefficient of the drive motor

S: $\quad$ The effective cross-sectional area of the inflation valve

$\operatorname{sign}\left(\omega_{c}\right)$ : Rotation direction of the ball mill

$t_{i}$ : Inflation time of the air clutch

$T_{f}: \quad$ Friction torque

$T_{L}$ : $\quad$ Load torque

$T_{r}: \quad$ The electromagnetic time constant of the rotor

$T_{e}: \quad$ The electromagnetic torque

$V$ : $\quad$ The air tube volume

$\alpha: \quad$ The deflection angle of the mill 
$\mu_{1}$ : The coefficient of frictional torque

$\sigma$ : The leakage coefficient of the motor

$\tau$ : Time constant.

\section{Data Availability}

The data used to support the findings of this study are available from the corresponding author upon request.

\section{Conflicts of Interest}

The authors declare that there are no conflicts of interest regarding the publication of this article.

\section{Acknowledgments}

This work was supported by the National Natural Science Foundation of China (Grant no. 51775225) and the Shanxi Province Coal Basic Key Technologies Research and Development Program (Grant no. MJ2014-02).

\section{References}

[1] M. V. Vijfeijken, A. Filidore, M. Walbert, and A. Marks, "Copper Mountain: Overview on the Grinding Mills and Their Dual Pinion Mill Drives," in SAG Conference, Vancouver, BC, Canada, September 2012.

[2] P. P. Castro and M. A. Valenzuela, "Space vector modeling of a SAG mill drive and evaluation during mill shutdowns," in Proceedings of the 51st Annual Meeting on IEEE Industry Application Society, IAS 2015, October 2015.

[3] P. P. Castro and M. A. Valenzuela, "Modeling and evaluation of cycloconverter-fed, two-stator windings SAG mill drive. Part II: Starting evaluation," in Proceedings of the 2014 IEEE Industry Application Society Annual Meeting, IAS 2014, October 2014.

[4] V. Guerrero and J. Pontt, "Oscillatory torque caused by dead time in the current control of high power gearless mills," in Proceedings of the 37th Annual Conference of the IEEE Industrial Electronics Society, IECON 2011, pp. 1966-1970, November 2011.

[5] T. Szolc, R. Konowrocki, M. Michajłow, and A. Prȩgowska, "An investigation of the dynamic electromechanical coupling effects in machine drive systems driven by asynchronous motors," Mechanical Systems and Signal Processing, vol. 49, no. 1-2, pp. 118-134, 2014.

[6] M. Laylabadi and A. Symonds, "An electrical impact study between variable speed dual pinion mills and gearless mill drives," in Proceedings of the 51st Annual Meeting on IEEE Industry Application Society, IAS 2015, pp. 1-9, October 2015.

[7] S. Morrell, "Modelling the influence on power draw of the slurry phase in Autogenous (AG), Semi-autogenous (SAG) and ball mills," Minerals Engineering, vol. 89, pp. 148-156, 2016.

[8] M. Zolghadri, M. Noaparast, and S. Z. Shafaei Tonkaboni, "A novel theory for energy considerations in breakage function," Powder Technology, vol. 331, pp. 338-345, 2018.

[9] J. L. Salazar, L. Magne, G. Acuña, and F. Cubillos, "Dynamic modelling and simulation of semi-autogenous mills," Minerals Engineering, vol. 22, no. 1, pp. 70-77, 2009.

[10] J.-L. Salazar, H. Valdés-González, E. Vyhmesiter, and F. Cubillos, "Model predictive control of semiautogenous mills (sag)," Minerals Engineering, vol. 64, pp. 92-96, 2014.
[11] N. Djordjevic, R. Morrison, B. Loveday, and P. Cleary, "Modelling comminution patterns within a pilot scale AG/SAG mill," Minerals Engineering, vol. 19, no. 15, pp. 1505-1516, 2006.

[12] P. W. Cleary, R. Morrisson, and S. Morrell, "Comparison of DEM and experiment for a scale model SAG mill," International Journal of Mineral Processing, vol. 68, no. 1-4, pp. 129-165, 2003.

[13] J. Larabee, B. Pellegrino, and B. Flick, "Induction motor starting methods and issues," in Proceedings of the 52nd Annual Petroleum and Chemical Industry Conference, pp. 217-222, September 2005.

[14] X. Bian, G. Wang, H. Wang, S. Wang, and W. Lv, "Effect of lifters and mill speed on particle behaviour, torque, and power consumption of a tumbling ball mill: Experimental study and DEM simulation," Minerals Engineering, vol. 105, pp. 22-35, 2017.

[15] B. Zhang, X. Wu, Z. Hu, and D. Zhou, "Analysis of Shifting Quality Based on AMT of the Electric Vehicle," in Proceedings of SAE-China Congress 2014: Selected Papers, vol. 328 of Lecture Notes in Electrical Engineering, pp. 97-104, Springer Berlin Heidelberg, Berlin, Heidelberg, Germany, 2015. 


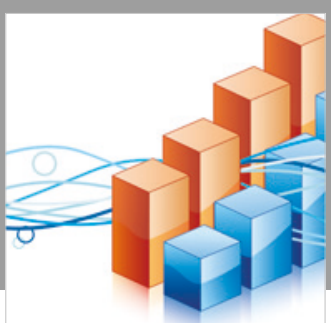

Advances in

Operations Research

\section{-n-m}
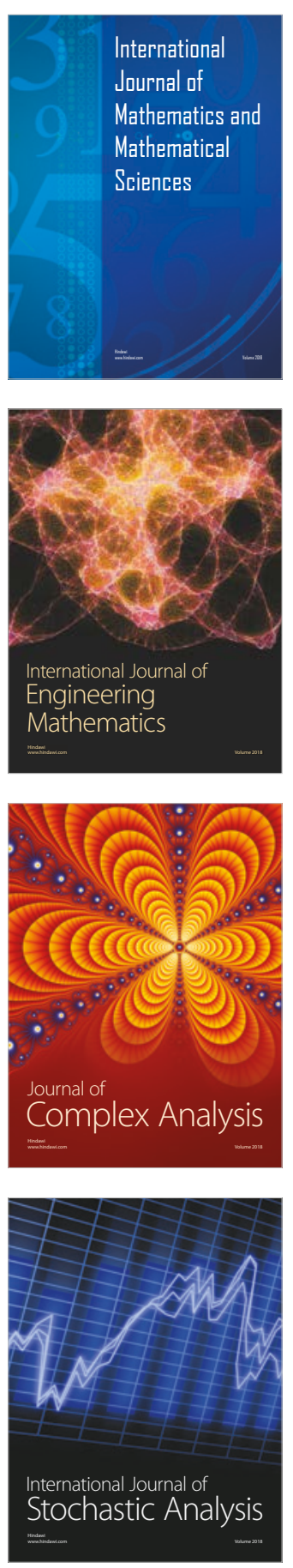
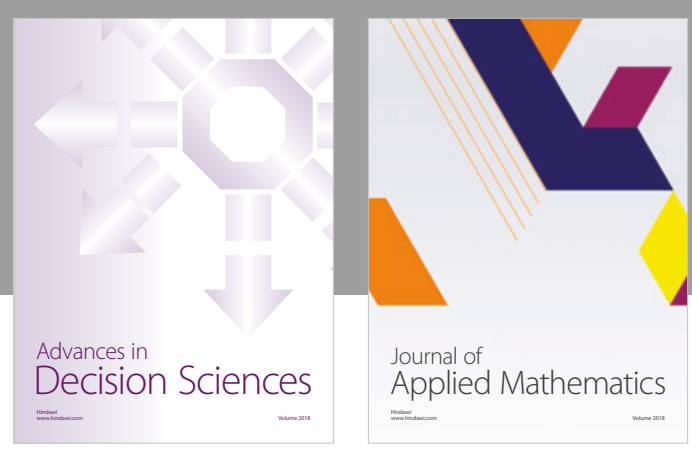

Journal of

Applied Mathematics
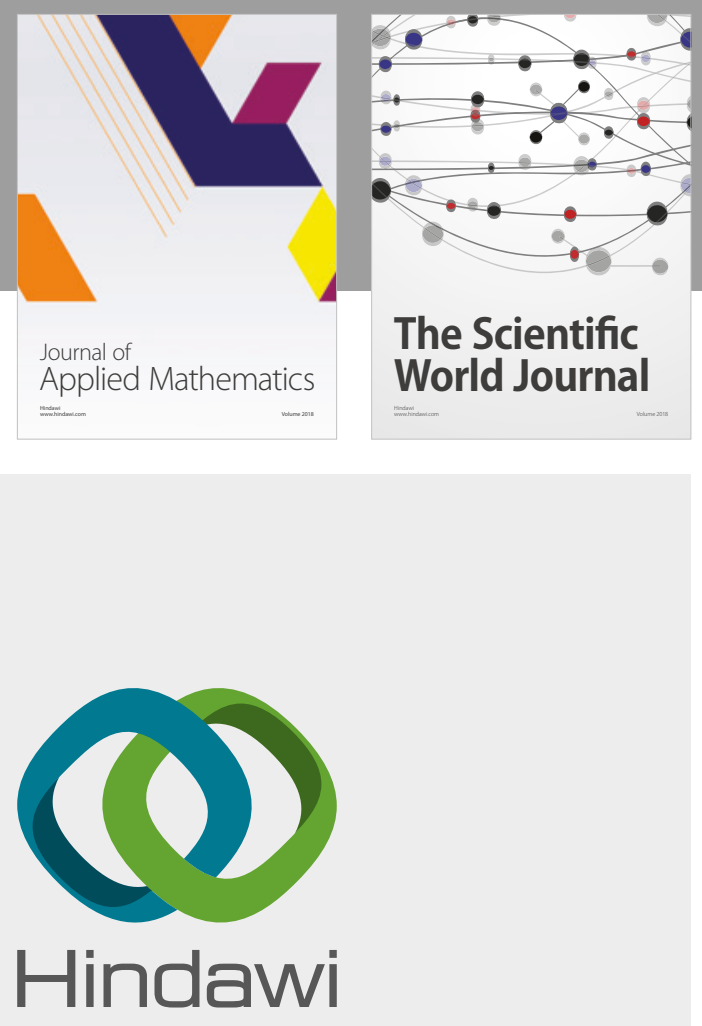

Submit your manuscripts at

www.hindawi.com

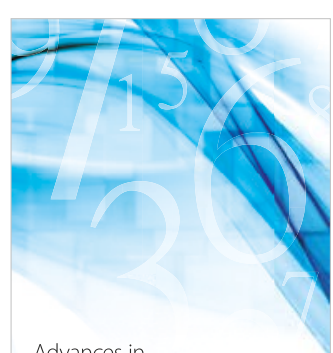

Advances in
Numerical Analysis
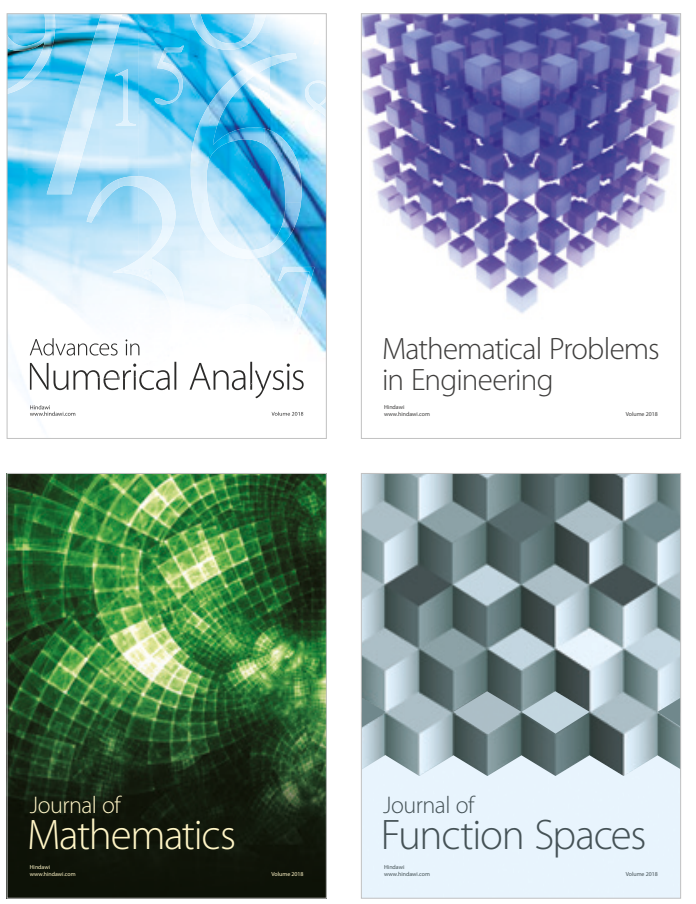

Mathematical Problems in Engineering

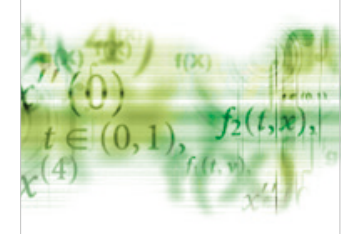

International Journal of

Differential Equations

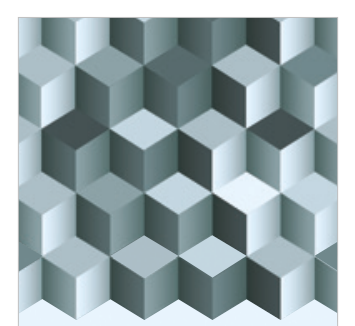

Journal of

Function Spaces

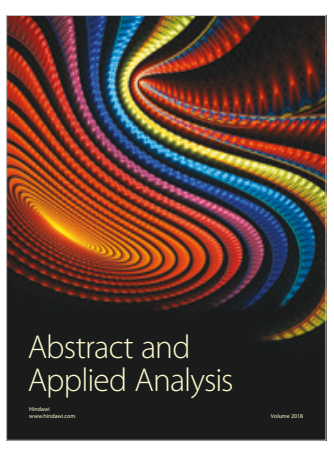

The Scientific

World Journal

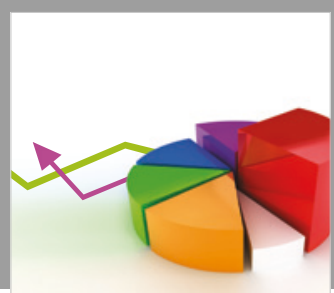

Journal of

Probability and Statistics
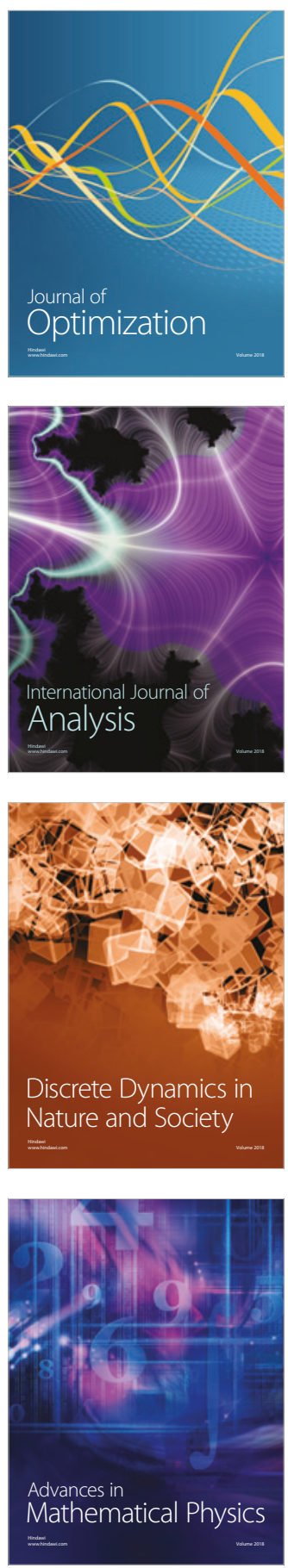